\title{
Targeting Peptides with an Iron-Based Oxidant: Cleavage of the Amino Acid Backbone and Oxidation of Side Chains
}

\author{
Anil R. Ekkati and Jeremy J. Kodanko* \\ Wayne State University, Department of Chemistry, 5101 Cass Ave, \\ Detroit, Michigan 48202 \\ Supporting Information \\ (48 Pages)
}

Part A. General Considerations: p 2-3

Part B. Experimental procedures and tabulated characterization data for new compounds:

p 4-18

Part C. Kinetic Studies: p 19-22

Part D. References: $\mathrm{p} 23$

Part E. ${ }^{1} \mathrm{H}$ and ${ }^{13} \mathrm{C}$ NMR spectra for all new compounds: $\mathrm{p}$ 24-48 
Part A. General Considerations

All reagents were purchased from commercial suppliers and used as received. NMR spectra were recorded on a Varian FT-NMR Mercury-400 or $500 \mathrm{MHz}$ Spectrometer. Mass spectra were recorded on a Waters ZQ2000 single quadrupole mass spectrometer using an electrospray ionization source. IR spectra were recorded on a Nicolet FT-IR spectrophotometer. HPLC was performed on an Agilent 1200 Preparative Purification System equipped with a multi-wavelength detector. UV-vis spectra were recorded on a Varian Cary 50 spectrophotometer and a $10 \mathrm{~mm}$ path length cell was used for the experiments. The complexes $\left[\mathrm{Fe}^{\mathrm{II}}(\mathrm{N} 4 \mathrm{Py})\left(\mathrm{CH}_{3} \mathrm{CN}\right)\right]\left(\mathrm{ClO}_{4}\right)_{2} \quad(\mathbf{8}){ }^{1}$ $\left[\mathrm{Fe}^{\mathrm{II}}(\mathrm{TPA})(\mathrm{OTf})_{2}\right](\mathbf{9}),{ }^{2}$ and $\left[\mathrm{Fe}^{\mathrm{II}}(\mathrm{BPMEN})(\mathrm{OTf})_{2}\right](\mathbf{1 0})^{3}$ (see Figure $\mathrm{S} 1$ for ligand structures) used in this study were synthesized according to the literature procedures. $\mathrm{N}$ Acetyl-amino acids were synthesized from commercially available amino acids using standard literature procedures. ${ }^{4}$ EDTA-based Chelex 100 resin was purchased from BIORAD Laboratories, Inc. All reactions were performed under ambient atmosphere unless otherwise noted. Anaerobic reactions were performed in Schlenk tubes. These reactions were deoxygenated by performing five vacuum-backfill cycles with Ar and were run under a constant purge of Ar.

Caution: Perchlorate salts are potentially explosive and should be handled with care. 
Compound abbreviations are as follows:

N4Py: $N, N$-bis(2-pyridylmethyl)- $N$-(bis-2-pyridylmethyl)amine

TPA: Tris(2-pyridylmethyl)amine

BPMEN: $N, N^{\prime}$-dimethyl- $N, N^{\top}$-bis(2-pyridylmethyl)ethane-1,2-diamine

DCC: Dicyclohexylcarbodiimide

HBTU: 2-(1H-benzotriazole-1-yl)-1,1,3,3-tetramethyluronium hexafluorophosphate HOBt: Hydroxybenzotriazole

EDAC: 1-Ethyl-3-(3-dimethylaminopropyl)carbodiimide hydrochloride

Figure S1. Structures of N4Py, TPA and BPMEN.<smiles>N#[W+]N(Cc1ccccn1)C(c1ccccn1)c1ccccn1</smiles><smiles>CC(C)C</smiles><smiles>CN(CCN(C)Cc1ccccn1)Cc1ccccn1</smiles> 
Part B. Experimental procedures and tabulated characterization data for new compounds

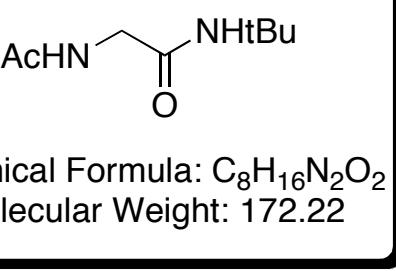

2-Acetamido- $N$-tert-butylacetamide (1). A mixture of $N$-acetyl-glycine $(5.00 \mathrm{~g}, 42.7$ mmol), p-nitrophenol (5.93 g, $42.7 \mathrm{mmol})$, DCC (8.80 g, $42.7 \mathrm{mmol})$, and $\mathrm{CH}_{2} \mathrm{Cl}_{2}(75$ $\mathrm{mL}$ ) was heated to $50{ }^{\circ} \mathrm{C}$ under an inert atmosphere with vigorous stirring for $2 \mathrm{~h}$. After cooling to $\mathrm{rt}$, the reaction mixture was filtered through a bed of celite, and the filter cake was washed with $\mathrm{CH}_{2} \mathrm{Cl}_{2}(25 \mathrm{~mL})$. The filtrate was concentrated to give crude ester $(13.00 \mathrm{~g})$. The crude ester was purified by recrystallization from hot ethyl acetate (75 $\mathrm{mL})$ to give the $p$-nitrophenol ester $(4.50 \mathrm{~g}, 44 \%)$ as a light yellow solid. ${ }^{1} \mathrm{H}$ NMR $\left(\mathrm{CDCl}_{3}\right) \delta 8.26(\mathrm{dd}, J=7.3,2.4 \mathrm{~Hz}, 2 \mathrm{H}), 7.29(\mathrm{dd}, J=7.3,2.4 \mathrm{~Hz}, 2 \mathrm{H}), 6.05$ (brs, $\left.1 \mathrm{H}\right)$, $4.30(\mathrm{~d}, J=5.6 \mathrm{~Hz}, 2 \mathrm{H}), 2.08(\mathrm{~s}, 3 \mathrm{H})$.

A mixture of the $p$-nitrophenol ester $(4.50 \mathrm{~g}, 18.9 \mathrm{mmol})$ and $\mathrm{CH}_{2} \mathrm{Cl}_{2}(100 \mathrm{~mL})$ was stirred for 5 min and the mixture was filtered through a bed of celite to remove any undissolved portion. tert-Butylamine $(4.4 \mathrm{~mL}, 42 \mathrm{mmol})$ was added to the $\mathrm{CH}_{2} \mathrm{Cl}_{2}$ solution, resulting in formation of bright yellow precipitate. The reaction was maintained at $\mathrm{rt}$, and more tert-butylamine $(2.2 \mathrm{~mL}, 21 \mathrm{mmol})$ was added, until TLC analysis of the reaction $(30 \mathrm{~min})$ indicated that the $p$-nitrophenol ester was consumed. The reaction mixture was filtered through a bed of celite, and the filter cake was washed with $\mathrm{CH}_{2} \mathrm{Cl}_{2}$ $(15 \mathrm{~mL})$. The filtrate was concentrated to give crude product as a yellow solid $(2.50 \mathrm{~g})$. The crude product was purified by recrystallization from hot ethyl acetate $(100 \mathrm{~mL})$ to give $1(2.0 \mathrm{~g}, 61 \%)$ as a white solid. m.p. $=161-162{ }^{\circ} \mathrm{C} ;{ }^{1} \mathrm{H}$ NMR $\left(\mathrm{DMSO}-\mathrm{d}_{6}\right) \delta 7.94$ 
(brs, 1H), $7.41(\mathrm{~s}, 1 \mathrm{H}), 3.59(\mathrm{~d}, J=6.5 \mathrm{~Hz}, 2 \mathrm{H}), 1.82(\mathrm{~s}, 3 \mathrm{H}), 1.23(\mathrm{~s}, 9 \mathrm{H}) ;{ }^{13} \mathrm{C}$ NMR $\left(\right.$ DMSO-d $\left._{6}\right) \delta 169.3,168.1,50.0,42.2,28.5,22.4$; IR (KBr) 3280, 3083, 2972, 2929, $2851,1638,1561,1426,1371,1282 \mathrm{~cm}^{-1}$; LRMS (ESMS) calcd for $\mathrm{C}_{8} \mathrm{H}_{17} \mathrm{~N}_{2} \mathrm{O}_{2}(\mathrm{M}+\mathrm{H})^{+}$: 173, found: 173 .

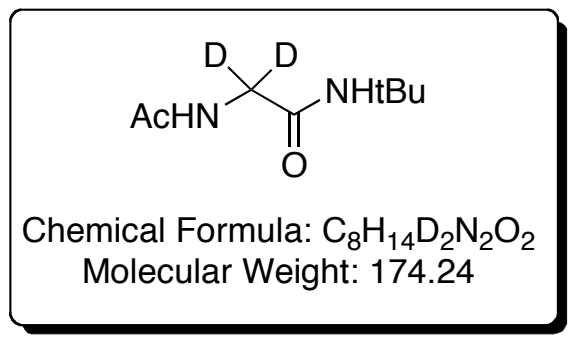

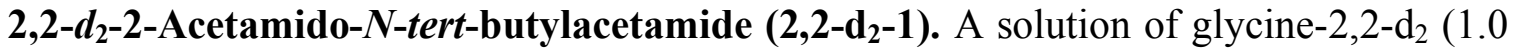
g, $13 \mathrm{mmol})$, acetic anhydride $(15 \mathrm{~mL}, 160 \mathrm{mmol})$, and $\mathrm{D}_{2} \mathrm{O}(2.5 \mathrm{~mL})$ was stirred at $\mathrm{rt}$. After $3 \mathrm{~h}$, the reaction flask was cooled to $-20{ }^{\circ} \mathrm{C}$ for $0.5 \mathrm{~h}$. The white solid formed was collected by filtration and dried in a vacuum desiccator over $\mathrm{P}_{2} \mathrm{O}_{5}$ and $\mathrm{KOH}$ to yield $\mathrm{N}$ acetyl-glycine- $d_{2}(0.400 \mathrm{~g}, 25 \%)$.

tert-Butylamine $(1.0 \mathrm{ml}, 10 \mathrm{mmol})$ was added dropwise to a mixture of $N$-acetylglycine-2,2- $d_{2}(0.4 \mathrm{~g}, 3.4 \mathrm{mmol})$, HBTU $(1.07 \mathrm{~g}, 3.36 \mathrm{mmol})$, and THF $(50 \mathrm{~mL})$. This reaction mixture was vigorously stirred at $\mathrm{rt}$ under an inert atmosphere. After $2 \mathrm{~h}$, the THF was removed under reduced pressure and the resulting residue was dissolved in $10 \mathrm{~mL}$ of water and extracted with EtOAc $(3 \times 50 \mathrm{~mL})$. The combined organic layers were washed with $\mathrm{NH}_{4} \mathrm{Cl}$ solution $(1 \times 20 \mathrm{~mL}), 5 \% \mathrm{NaHCO}_{3}$ solution $(1 \times 20 \mathrm{~mL})$, dried $\left(\mathrm{Na}_{2} \mathrm{SO}_{4}\right)$, and concentrated. Crude product was purified by silica gel chromatography (5\% $\left.\mathrm{MeOH}: \mathrm{CHCl}_{3}\right)$ followed by recrystallization from EtOAc to give 2,2- $d_{2}-\mathbf{1}(0.100 \mathrm{~g}, 17 \%)$ as a white solid. ${ }^{1} \mathrm{H} \mathrm{NMR}\left(\mathrm{CDCl}_{3}\right) \delta 7.90(\mathrm{~s}, 1 \mathrm{H}), 7.39(\mathrm{~s}, 1 \mathrm{H}), 3.58(\mathrm{~d}, J=5.8 \mathrm{~Hz}, 0.1 \mathrm{H}$, 
$1.82(\mathrm{~s}, 3 \mathrm{H}), 1.23(\mathrm{~s}, 9 \mathrm{H})$; LRMS (ESMS) calcd for $\mathrm{C}_{8} \mathrm{H}_{14} \mathrm{D}_{2} \mathrm{~N}_{2} \mathrm{O}_{2} \mathrm{Na}(\mathrm{M}+\mathrm{Na})^{+}$: 197 , found: 197.

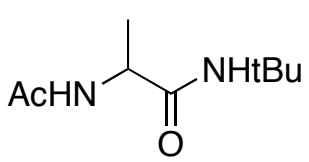

Chemical Formula: $\mathrm{C}_{9} \mathrm{H}_{18} \mathrm{~N}_{2} \mathrm{O}_{2}$ Molecular Weight: 186.25

2-Acetamido- $N$-tert-butylpropanamide (2). A mixture of $N$-acetyl-alanine $(10.00 \mathrm{~g}$, $76.26 \mathrm{mmol})$, p-nitrophenol (10.60 g, $76.26 \mathrm{mmol})$, DCC (15.73 g, $76.26 \mathrm{mmol})$, and EtOAc $(150 \mathrm{~mL})$ was vigorously stirred under an inert atmosphere. After stirring at $\mathrm{rt}$ for $6 \mathrm{~h}$, the reaction mixture was kept in freezer for overnight. After warming to $\mathrm{rt}$, the reaction mixture was filtered through a bed of celite. The filtrate was concentrated to give the $p$-nitrophenol ester $(8.0 \mathrm{~g}, 42 \%)$ as a light yellow solid. ${ }^{1} \mathrm{H} \mathrm{NMR}\left(\mathrm{CDCl}_{3}\right) \delta 8.27(\mathrm{~d}, J$ $=9.7 \mathrm{~Hz}, 2 \mathrm{H}), 7.29(\mathrm{~d}, J=9.7 \mathrm{~Hz}, 2 \mathrm{H}), 6.07(\mathrm{brs}, 1 \mathrm{H}), 4.79(\mathrm{~m}, 1 \mathrm{H}), 2.07(\mathrm{~s}, 3 \mathrm{H}), 1.59$ $(\mathrm{d}, J=7.3 \mathrm{~Hz}, 3 \mathrm{H})$.

A mixture of $p$-nitrophenol ester $(8.00 \mathrm{~g}, 31.7 \mathrm{mmol})$, tert-butylamine (13.5 $\mathrm{mL}$, $128 \mathrm{mmol})$, and $\mathrm{CH}_{2} \mathrm{Cl}_{2}(100 \mathrm{~mL})$ was vigorously stirred under an inert atmosphere. After stirring the reaction mixture at $\mathrm{rt}$ for $3 \mathrm{~h}$, the reaction mixture was filtered through a bed of celite, and the filter cake was washed with $\mathrm{CH}_{2} \mathrm{Cl}_{2}$. The filtrate was concentrated to give crude product as a dark yellow solid. The crude product was purified by recrystallization from hot ethanol to give $2(4.2 \mathrm{~g}, 71 \%)$ as a white solid. m.p. $=159-160$ ${ }^{\circ} \mathrm{C} ;{ }^{1} \mathrm{H}$ NMR $\left(\mathrm{CDCl}_{3}\right) \delta 6.32$ (brs, $\left.1 \mathrm{H}\right), 6.06$ (brs, $\left.1 \mathrm{H}\right), 4.37-4.31$ (m, 1H), $1.98(\mathrm{~s}, 3 \mathrm{H})$, 1.35-1.29 (m, 12H); ${ }^{13} \mathrm{C} \mathrm{NMR}\left(\mathrm{CDCl}_{3}\right) \delta 171.6,169.9,51.3,49.2,28.6,23.2,18.7$; IR 
(KBr) 3287, 3084, 2977, 1682, 1633, 1561, 1541, 1456, 1393, 1367, 1256, 1229, 701, $602 \mathrm{~cm}^{-1}$; LRMS (ESMS) calcd for $\mathrm{C}_{9} \mathrm{H}_{19} \mathrm{~N}_{2} \mathrm{O}_{2}(\mathrm{M}+\mathrm{H})^{+}:$187, found: 187.

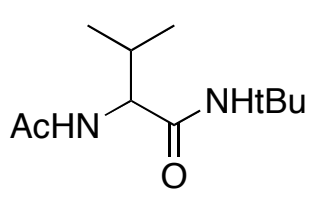

Chemical Formula: $\mathrm{C}_{11} \mathrm{H}_{22} \mathrm{~N}_{2} \mathrm{O}_{2}$ Molecular Weight: 214.30

2-Acetamido- $N$-tert-butyl-3-methylbutanamide (3). A mixture of $\mathrm{N}$-acetyl-valine (3.00 g, $18.8 \mathrm{mmol})$, -nitrophenol (2.62 g, $18.8 \mathrm{mmol})$, DCC (3.88 g, $18.8 \mathrm{mmol})$, and $\mathrm{CH}_{2} \mathrm{Cl}_{2}$ $(50 \mathrm{~mL})$ was heated to $50{ }^{\circ} \mathrm{C}$ under an inert atmosphere with vigorous stirring for $3 \mathrm{~h}$. After cooling to rt, the reaction mixture was filtered through a bed of celite, and the filter cake was washed with $\mathrm{CH}_{2} \mathrm{Cl}_{2}$. The filtrate was concentrated to give the $p$-nitrophenol ester $(4.2 \mathrm{~g}, 79 \%)$ as an oil. ${ }^{1} \mathrm{H} \mathrm{NMR}\left(\mathrm{CDCl}_{3}\right) \delta 8.26(\mathrm{~d}, J=9.1 \mathrm{~Hz}, 2 \mathrm{H}), 7.26(\mathrm{~d}, J=9.1$ Hz, 2H), 5.97 (brs, 1H), 4.75 (dd, $J=8.2,5.1 \mathrm{~Hz}, 1 \mathrm{H}), 2.36-2.29(\mathrm{~m}, 1 \mathrm{H}), 2.08(\mathrm{~s}, 3 \mathrm{H})$, $1.05(\mathrm{q}, J=9.7,6.7 \mathrm{~Hz}, 6 \mathrm{H})$.

A mixture of the $p$-nitrophenol ester $(4.2 \mathrm{~g}, 14.9 \mathrm{mmol})$, tert-butylamine (11.3 $\mathrm{mL}, 107 \mathrm{mmol})$, and $\mathrm{CH}_{2} \mathrm{Cl}_{2}(50 \mathrm{~mL})$ was vigorously stirred under an inert atmosphere. After stirring the reaction mixture at $\mathrm{rt}$ for $16 \mathrm{~h}$, the reaction mixture was filtered through a bed of celite, and the filter cake was washed with $\mathrm{CH}_{2} \mathrm{Cl}_{2}$. The filtrate was concentrated to give crude product as a dark yellow solid. The crude product was purified by recrystallization from ethyl acetate $(100 \mathrm{~mL})$ to give $3(1.3 \mathrm{~g}, 40 \%)$. m.p. $=193-194{ }^{\circ} \mathrm{C}$; ${ }^{1} \mathrm{H} \mathrm{NMR}\left(\mathrm{CDCl}_{3}\right) \delta 6.28$ (brs, 1H), 5.74 (brs, $\left.1 \mathrm{H}\right), 4.05$ (appt, $\left.J=8.1 \mathrm{~Hz}, 1 \mathrm{H}\right), 2.03-1.94$ (m, 4H), $1.32(\mathrm{~s}, 9 \mathrm{H}), 0.91(\mathrm{dd}, J=6.4,2.4 \mathrm{~Hz}, 6 \mathrm{H}) ;{ }^{13} \mathrm{C}$ NMR $\left(\right.$ DMSO-d $\left._{6}\right) \delta 170.5$, 
$168.9,57.7,50.0,30.9,28.4,22.5,19.1,18.2$; IR (thin film) 3429, 3277, 3083, 2965, 1637, 1560, 1381, $1367 \mathrm{~cm}^{-1}$; LRMS (ESMS) calcd for $\mathrm{C}_{11} \mathrm{H}_{23} \mathrm{~N}_{2} \mathrm{O}_{2}(\mathrm{M}+\mathrm{H})^{+}:$: 215, found: 215.

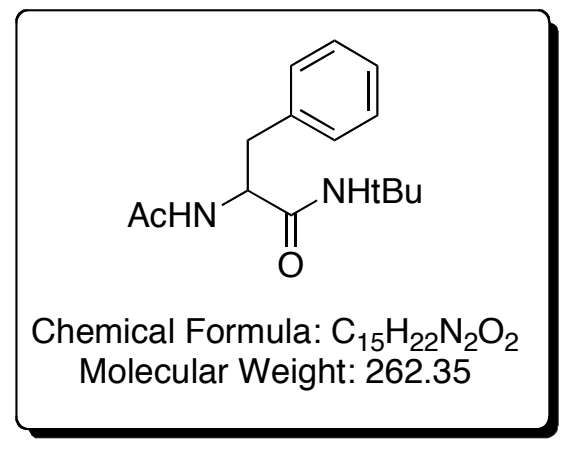

2-Acetamido- $N$-tert-butyl-3-phenylpropanamide (4). A mixture of $N$-acetylphenylalanine (14.0 g, $67.6 \mathrm{mmol})$, -nitrophenol (9.39 g, $67.6 \mathrm{mmol})$, DCC (13.93 g, $67.60 \mathrm{mmol})$, and $\mathrm{CH}_{2} \mathrm{Cl}_{2}(215 \mathrm{~mL})$ was heated to $50{ }^{\circ} \mathrm{C}$ under an inert atmosphere with vigorous stirring for $8 \mathrm{~h}$. After cooling to $\mathrm{rt}$, the reaction mixture was filtered through a bed of celite. The filtrate was concentrated to give crude product $(18.50 \mathrm{~g})$. The crude product was purified by recrystallization from hot ethyl acetate to give the $p$-nitrophenol ester $(14.00 \mathrm{~g}, 63 \%)$ as a light yellow solid. ${ }^{1} \mathrm{H}$ NMR $\left(\mathrm{CDCl}_{3}\right) \delta 8.22(\mathrm{~d}, J=8.9 \mathrm{~Hz}, 2 \mathrm{H})$, 7.36-7.13 (m, 5H), $7.11(\mathrm{~d}, J=8.9 \mathrm{~Hz}, 2 \mathrm{H}), 5.95(\mathrm{~d}, J=7.3 \mathrm{~Hz}, 1 \mathrm{H}), 5.04(\mathrm{dd}, J=13.7$, $6.5 \mathrm{~Hz}, 1 \mathrm{H}), 3.29-3.18(\mathrm{~m}, 2 \mathrm{H}), 2.02(\mathrm{~s}, 3 \mathrm{H})$.

A mixture of $p$-nitrophenol ester $(5.00 \mathrm{~g}, 15.2 \mathrm{mmol})$, tert-butylamine $(8.0 \mathrm{~mL}, 75$ mmol), and $\mathrm{CH}_{2} \mathrm{Cl}_{2}(150 \mathrm{~mL})$ was heated to $50{ }^{\circ} \mathrm{C}$ under an inert atmosphere with vigorous stirring, resulting in formation of bright yellow precipitate, for $12 \mathrm{~h}$. After cooling to rt, the reaction mixture was filtered through a bed of celite. The filtrate was concentrated to give a dark yellow crude product $(5.00 \mathrm{~g})$. The crude product was 
purified by recrystallization from hot ethanol $(75 \mathrm{~mL})$ to give $4(2.5 \mathrm{~g}, 62 \%)$ as a white solid. m.p. $=220-221{ }^{\circ} \mathrm{C} ;{ }^{1} \mathrm{H}$ NMR $\left(\mathrm{CDCl}_{3}\right) \delta$ 7.31-7.21 (m, 5H), $6.49(\mathrm{~d}, J=7.3 \mathrm{~Hz}$, 1H), 5.30 (brs, 1H), 4.51-4.45 (m, 1H), 3.10 (dd, $J=13.0,5.6 \mathrm{~Hz}, 1 \mathrm{H}), 2.85$ (dd, $J=$ 13.3, $9.3 \mathrm{~Hz}, 1 \mathrm{H}), 1.98$ (s, 3H), 1.16 (s, 9H); ${ }^{13} \mathrm{C}$ NMR (DMSO-d 6 ) $\delta 170.5,168.9,137.9$, 129.3, 127.9, 126.2, 54.1, 50.1, 38.4, 28.4, 22.5; IR (KBr) 3265, 3080, 2966, 1671, 1643, $1561,1449,1392,1366,1286,741,701 \mathrm{~cm}^{-1}$; LRMS (ESMS) calcd for $\mathrm{C}_{15} \mathrm{H}_{23} \mathrm{~N}_{2} \mathrm{O}_{2}$ $(\mathrm{M}+\mathrm{H})^{+}: 263$, found: 263 .

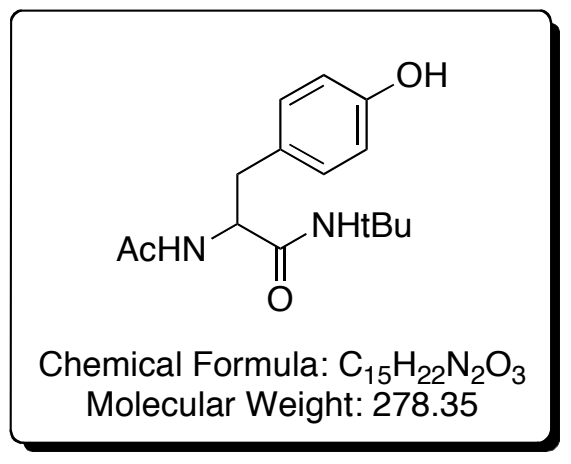

2-Acetamido- $\mathrm{N}$-tert-butyl-3-(4-hydroxyphenyl)propanamide (5). A mixture of $\mathrm{N}$ acetyl-tyrosine $(6.5 \mathrm{~g}, 29 \mathrm{mmol})$, tert-butylamine $(6.5 \mathrm{~mL}, 62 \mathrm{mmol})$, HOBt $(4.0 \mathrm{~g}, 30$ mmol), EDAC (5.6 g, $30 \mathrm{mmol})$, and DMF $(150 \mathrm{~mL})$ was vigorously stirred under an inert atmosphere. After stirring for $20 \mathrm{~h}$ at rt, DMF was removed under reduced pressure. Water $(50 \mathrm{~mL})$ was added to the residue and the mixture was extracted with EtOAc $(3 \times$ $50 \mathrm{~mL})$. The combined organic layers were washed with $1 \mathrm{M} \mathrm{HCl}$ solution $(1 \times 50 \mathrm{~mL})$, $5 \% \mathrm{NaHCO}_{3}$ solution $(1 \times 50 \mathrm{~mL})$, brine solution $(1 \times 50 \mathrm{~mL})$, dried $\left(\mathrm{Na}_{2} \mathrm{SO}_{4}\right)$, and concentrated to give crude product. The crude product was purified by recrystallization from hot ethyl acetate to give $5(3.0 \mathrm{~g}, 37 \%)$ as a white solid. m.p. $=203-204{ }^{\circ} \mathrm{C} ;{ }^{1} \mathrm{H}$ NMR (DMSO-d 6$) \delta 9.19(\mathrm{~s}, 1 \mathrm{H}), 7.89(\mathrm{~d}, J=8.1 \mathrm{~Hz}, 1 \mathrm{H}), 7.43(\mathrm{~s}, 1 \mathrm{H}), 6.99(\mathrm{~d}, J=8.1$ 
Hz, 2H), $6.61(\mathrm{~d}, J=8.9 \mathrm{~Hz}, 2 \mathrm{H}), 4.39-4.33(\mathrm{~m}, 1 \mathrm{H}), 2.72(\mathrm{dd}, J=13.8,5.7 \mathrm{~Hz}, 1 \mathrm{H})$, $2.59(\mathrm{dd}, J=13.8,8.9 \mathrm{~Hz}, 1 \mathrm{H}), 1.74(\mathrm{~s}, 3 \mathrm{H}), 1.18(\mathrm{~s}, 9 \mathrm{H}) ;{ }^{13} \mathrm{C}$ NMR $\left(\right.$ DMSO-d $\left._{6}\right) \delta$ 170.7, 168.7, 155.6, 130.2, 128.0, 114.7, 54.4, 50.0, 37.5, 28.4, 22.5; IR (KBr) 3335, 3266, 3090, 2975, 1650, 1627, 1591, 1550, 1517, 1451, 1392, 1365, 1269, $1225 \mathrm{~cm}^{-1}$; LRMS (ESMS) calcd for $\mathrm{C}_{15} \mathrm{H}_{23} \mathrm{~N}_{2} \mathrm{O}_{3}(\mathrm{M}+\mathrm{H})^{+}: 279$, found: 279 .

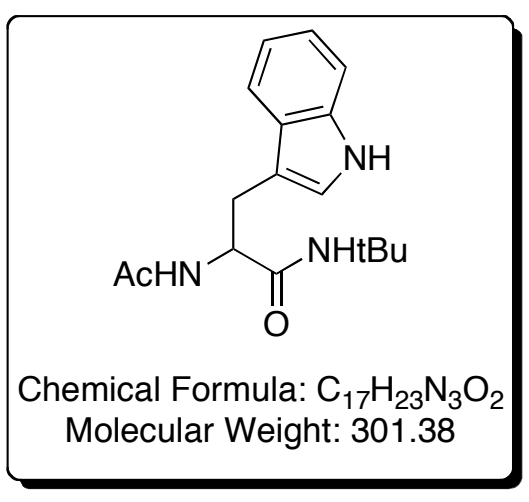

2-Acetamido- $N$-tert-butyl-3-(1H-indol-3-yl)propanamide (6). A mixture of $N$-acetyltryptophan (10.00 g, $40.60 \mathrm{mmol}), p$-nitrophenol (5.64 g, $40.6 \mathrm{mmol})$, DCC (8.37 g, 40.6 $\mathrm{mmol})$, and EtOAc $(150 \mathrm{~mL})$ was vigorously stirred under an inert atmosphere. After stirring at $\mathrm{rt}$ for $6 \mathrm{~h}$, the reaction mixture was kept in the freezer overnight. The reaction mixture was filtered through a bed of celite and the filtrate was concentrated to give the $p$-nitrophenol ester $(10.00 \mathrm{~g}, 67 \%)$ as a light yellow solid. ${ }^{1} \mathrm{H}$ NMR $\left(\mathrm{CDCl}_{3}\right) \delta 8.25$ (brs, $1 \mathrm{H}), 8.19(\mathrm{~d}, J=9.7 \mathrm{~Hz}, 1 \mathrm{H}), 7.58(\mathrm{~d}, J=8.1 \mathrm{~Hz}, 1 \mathrm{H}), 7.41(\mathrm{~d}, J=8.1 \mathrm{~Hz}, 1 \mathrm{H}), 7.25-$ 7.09 (m, 5H), 7.03 (d, $J=8.9 \mathrm{~Hz}, 1 \mathrm{H}), 6.07$ (brd, $J=6.5 \mathrm{~Hz}, 1 \mathrm{H}), 5.14-5.12(\mathrm{~m}, 1 \mathrm{H})$, 3.49-3.44 (m, 2H), $2.02(\mathrm{~s}, 3 \mathrm{H})$.

A mixture of $p$-nitrophenol ester $(10.00 \mathrm{~g}, 27.22 \mathrm{mmol})$, tert-butylamine $(20 \mathrm{~mL}$, $189 \mathrm{mmol})$, and $\mathrm{CH}_{2} \mathrm{Cl}_{2}(100 \mathrm{~mL})$ was heated to $50{ }^{\circ} \mathrm{C}$ under an inert atmosphere with vigorous stirring for $3 \mathrm{~h}$. After cooling to rt, the reaction mixture was filtered through a 
bed of celite, and the filter cake was washed with $\mathrm{CH}_{2} \mathrm{Cl}_{2}$. The filtrate was concentrated to give crude product as a brown solid. The crude product was purified by recrystallization from hot ethanol to give $6(1.3 \mathrm{~g}, 16 \%)$ as a white solid. m.p. $=209-210$ ${ }^{\circ} \mathrm{C} ;{ }^{1} \mathrm{H}$ NMR (DMSO-d $)$ ) $\delta 10.76(\mathrm{brs}, 1 \mathrm{H}), 7.92(\mathrm{~d}, J=8.1 \mathrm{~Hz}, 1 \mathrm{H}), 7.59(\mathrm{~d}, J=8.1 \mathrm{~Hz}$, 1H), $7.44(\mathrm{~s}, 1 \mathrm{H}), 7.29(\mathrm{~d}, J=8.1 \mathrm{~Hz}, 1 \mathrm{H}), 7.09(\mathrm{~d}, J=1.6 \mathrm{~Hz}, 1 \mathrm{H}), 7.03(\mathrm{t}, J=8.1 \mathrm{~Hz}$, 1H), $6.95(\mathrm{t}, J=8.1 \mathrm{~Hz}, 1 \mathrm{H}), 4.51-4.46(\mathrm{~m}, 1 \mathrm{H}), 2.99(\mathrm{dd}, J=14.6,5.7 \mathrm{~Hz}, 1 \mathrm{H}), 2.86$ $(\mathrm{dd}, J=14.6,8.1 \mathrm{~Hz}, 1 \mathrm{H}), 1.76(\mathrm{~s}, 3 \mathrm{H}), 1.19(\mathrm{~s}, 9 \mathrm{H}) ;{ }^{13} \mathrm{C} \mathrm{NMR}\left(\mathrm{CDCl}_{3}+\mathrm{DMSO}^{\mathrm{d}}{ }_{6}\right) \delta$ $169.6,168.6,135.2,126.4,122.2,120.0,117.5,117.4,110.2,109.2,52.9,49.5,27.4$, 26.9, 21.8; IR (thin film) 3415, 3268, 3083, 2975, 1664, 1635, 1546, 1478, 1461, 1391, $1359,1316,1291,1243,1222,741 \mathrm{~cm}^{-1}$; LRMS (ESMS) calcd for $\mathrm{C}_{17} \mathrm{H}_{24} \mathrm{~N}_{3} \mathrm{O}_{2}(\mathrm{M}+\mathrm{H})^{+}$: 302, found: 302 .

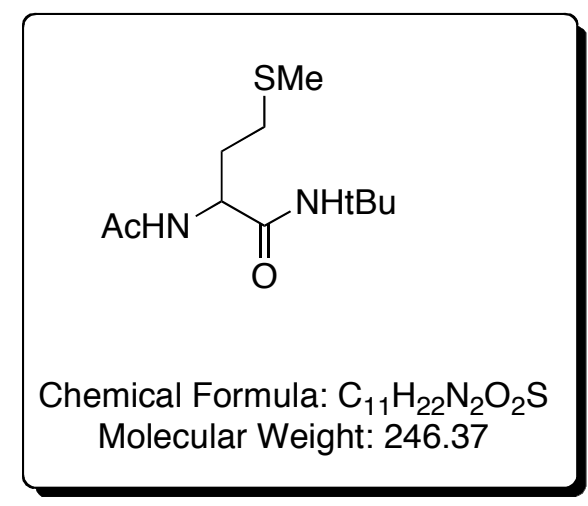

2-Acetamido- $N$-tert-butyl-4-(methylthio)butanamide (7). A mixture of $\mathrm{N}$-acetylmethionine (1.0 g, $5.2 \mathrm{mmol})$, tert-butylamine $(0.55 \mathrm{~mL}, 5.20 \mathrm{mmol})$, DCC $(1.07 \mathrm{~g}, 5.20$ mmol), and $\mathrm{CH}_{2} \mathrm{Cl}_{2}(25 \mathrm{~mL})$ was vigorously stirred under an inert atmosphere. After stirring for $24 \mathrm{~h}$ at $\mathrm{rt}$, the reaction mixture was filtered through a bed of celite and the filtrate was concentrated to give crude product. The crude product was purified by recrystallization from hot EtOAc to give $7(0.58 \mathrm{~g}, 45 \%)$ as a white solid. m.p. $=154-$ 
$155{ }^{\circ} \mathrm{C} ;{ }^{1} \mathrm{H}$ NMR $\left(\right.$ DMSO-d $\left._{6}\right) \delta 7.92(\mathrm{~d}, J=8.9 \mathrm{~Hz}, 1 \mathrm{H}), 7.50$ (brs, 1H), 4.28-4.22 (m, $1 \mathrm{H}), 2.42-2.30(\mathrm{~m}, 2 \mathrm{H}), 2.01(\mathrm{~s}, 3 \mathrm{H}), 1.82(\mathrm{~s}, 3 \mathrm{H}), 1.80-1.64(\mathrm{~m}, 2 \mathrm{H}), 1.22(\mathrm{~s}, 9 \mathrm{H}) ;{ }^{13} \mathrm{C}$ NMR $\left(\right.$ DMSO-d $\left._{6}\right) \delta 170.5,169.0,52.1,50.0,32.6,29.6,28.4,22.5,14.6$; IR (thin film) $3276,3080,2927,2854,2360,2341,2121,1636,1557,1449,1391,1365,1306,1292$, 1260, 1226, 1124, $812 \mathrm{~cm}^{-1}$; LRMS (ESMS) calcd for $\mathrm{C}_{11} \mathrm{H}_{23} \mathrm{~N}_{2} \mathrm{O}_{2} \mathrm{~S}(\mathrm{M}+\mathrm{H})^{+}: 247$, found: 247.

Oxidation studies of glycine substrate 1 with $\left[\mathrm{Fe}^{\mathrm{II}}(\mathrm{N} 4 \mathrm{Py}) \mathrm{CH}_{3} \mathrm{CN}\right]\left(\mathrm{ClO}_{4}\right)_{2}(8)$ and oxone. An orange-red color mixture of $1(20 \mathrm{mg}, 116 \mu \mathrm{mol}),\left[\mathrm{Fe}^{\mathrm{II}}(\mathrm{N} 4 \mathrm{Py}) \mathrm{CH}_{3} \mathrm{CN}\right]\left(\mathrm{ClO}_{4}\right)_{2}$ $(0.7 \mathrm{mg}, 1.0 \mu \mathrm{mol})$, and $\mathrm{D}_{2} \mathrm{O}-\mathrm{CD}_{3} \mathrm{CN}(4 \mathrm{~mL}, 3: 1)$ was stirred under an inert atmosphere at rt. After stirring for $5 \mathrm{~min}$, Oxone $(330 \mathrm{mg}, 536 \mu \mathrm{mol})$ in $2.0 \mathrm{~mL}$ of $\mathrm{D}_{2} \mathrm{O}$ was delivered by syringe pump over $1 \mathrm{~h}$. The formation of transient purple color followed by green color was observed during the addition of oxone solution. After stirring for $1 \mathrm{~h}$, the reaction mixture was filtered and $p$-nitrophenol $(36 \mu \mathrm{mol})$ was added and the solution was analyzed by ${ }^{1} \mathrm{HNMR}$ spectroscopy. Yields of the starting material 1 (17\%), aldehyde 11 (41\%), aldehyde 12 (11\%), $\alpha$-hydroxyglycine derivative 13 (5\%) and glyoxamide 14 (5\%) products were determined by ${ }^{1} \mathrm{HNMR}$ analysis with $p$-nitrophenol as an internal standard by integrating peaks at $8.91(\mathbf{1 1}), 5.32(\mathbf{1 2}), 5.68(\mathbf{1 3}), 2.23(\mathbf{1 4})$, and $6.93(p$ nitrophenol) ppm. In a separate experiment, this reaction was carried out under argon and the yields are as follows, starting material 1 (17\%), aldehyde 11 (31\%), aldehyde 12 (9\%), $\alpha$-hydroxyglycine derivative 13 (12\%) and glyoxamide 14 (5\%). The identities of compounds 11 and 12 were confirmed by comparison of their ${ }^{1} \mathrm{H}$ NMR and ESMS spectra with literature data. ${ }^{5,6}$ In a separate experiment performed using $\mathrm{H}_{2} \mathrm{O}$ and $\mathrm{MeCN}$ 
solvents compounds $\mathbf{1 3}$ and $\mathbf{1 4}$ were isolated by reverse phase HPLC after extracting the reaction mixture with $\mathrm{CHCl}_{3}$.

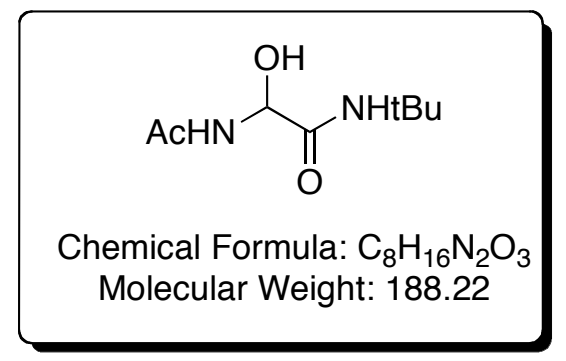

2-Acetamido- $\boldsymbol{N}$-tert-butyl-2-hydroxyacetamide (13). HPLC column Zorbax XDB-C18, 21.2 X $150 \mathrm{~mm}, 5$ micron equipped with guard column Zorbax XDB-C18, $21.2 \mathrm{~mm}, 5$ micron, flow rate $=20 \mathrm{~mL} / \mathrm{min}$, gradient elution 0-3 $\min 5 \% \mathrm{MeCN}: \mathrm{H}_{2} \mathrm{O}, 3-15 \min 95 \%$ $\mathrm{MeCN}: \mathrm{H}_{2} \mathrm{O}, \mathrm{T}_{\mathrm{R}}=2.5 \mathrm{~min} ;{ }^{1} \mathrm{H} \mathrm{NMR}\left(\mathrm{DMSO}_{-} \mathrm{d}_{6}\right) \delta 8.41(\mathrm{~d}, J=8.9 \mathrm{~Hz}, 1 \mathrm{H}), 7.29(\mathrm{~s}, 1 \mathrm{H})$, $6.28(\mathrm{~d}, J=5.6 \mathrm{~Hz}, 1 \mathrm{H}) ; 5.31(\mathrm{dd}, J=8.1,5.6 \mathrm{~Hz}, 1 \mathrm{H}), 1.83(\mathrm{~s}, 3 \mathrm{H}), 1.26(\mathrm{~s}, 9 \mathrm{H}) ;{ }^{13} \mathrm{C}$ NMR (DMSO-d $\left.{ }_{6}\right) \delta 169.5,168.7,71.4,50.0,28.3,22.7$; IR (thin film) 3334, 3290, 2974, $1642,1523,1365,1056 \mathrm{~cm}^{-1}$; LRMS (ESMS) calcd for $\mathrm{C}_{8} \mathrm{H}_{17} \mathrm{~N}_{2} \mathrm{O}_{3}(\mathrm{M}+\mathrm{H})^{+}: 189$, found: 189.

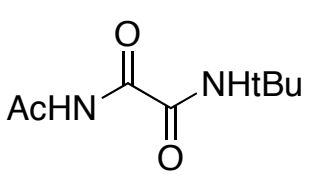

Chemical Formula: $\mathrm{C}_{8} \mathrm{H}_{14} \mathrm{~N}_{2} \mathrm{O}_{3}$ Molecular Weight: 186.21

$\boldsymbol{N}^{1}$-acetyl- $\boldsymbol{N}^{2}$-tert-butyloxalamide (14). HPLC column Zorbax XDB-C18, 21.2 X 150 mm, 5 micron equipped with guard column Zorbax XDB-C18, $21.2 \mathrm{~mm}, 5$ micron, flow 
rate $=20 \mathrm{~mL} / \mathrm{min}$, gradient elution $0-3 \min 5 \% \quad \mathrm{MeCN}: \mathrm{H}_{2} \mathrm{O}, 3-15 \min 5-95 \%$ MeCN: $\mathrm{H}_{2} \mathrm{O}, \mathrm{T}_{\mathrm{R}}=9.6$ min; ${ }^{1} \mathrm{H}$ NMR $\left(\mathrm{CDCl}_{3}\right) \delta 9.65$ (brs, 1H), 7.20 (brs, $\left.1 \mathrm{H}\right), 2.43$ (s, $3 \mathrm{H}), 1.37(\mathrm{~s}, 9 \mathrm{H}) ;{ }^{13} \mathrm{C} \mathrm{NMR}\left(\mathrm{CDCl}_{3}\right) \delta 170.7,159.2,157.1,52.0,28.1,24.9$; IR (thin film) $3339,2973,1772,1719,1689,1538,1473,1395,1370,1260,1226,1027,820,741$, 668, 582, $531 \mathrm{~cm}^{-1}$; LRMS (ESMS) calcd for $\mathrm{C}_{8} \mathrm{H}_{14} \mathrm{~N}_{2} \mathrm{O}_{3} \mathrm{Na}(\mathrm{M}+\mathrm{Na})^{+}:$209, found: 209.

\section{Oxidation studies of phenylalanine substrate 4 with $\left[\mathrm{Fe}^{\mathrm{II}}(\mathrm{N} 4 \mathrm{Py}) \mathrm{CH}_{3} \mathrm{CN}\right]\left(\mathrm{ClO}_{4}\right)_{2}(8)$} and oxone. An orange-red color mixture of 4 (50 mg, 190 umol), $\left[\mathrm{Fe}^{\mathrm{II}}(\mathrm{N} 4 \mathrm{Py}) \mathrm{CH}_{3} \mathrm{CN}\right]\left(\mathrm{ClO}_{4}\right)_{2}(12.6 \mathrm{mg}, 19.0 \mu \mathrm{mol})$, and $\mathrm{H}_{2} \mathrm{O}: \mathrm{CH}_{3} \mathrm{CN}(4 \mathrm{~mL}, 3: 1)$ was stirred at rt. After stirring for $5 \mathrm{~min}$, oxone $(352 \mathrm{mg}, 572 \mu \mathrm{mol})$ in $1 \mathrm{~mL}$ of $\mathrm{H}_{2} \mathrm{O}$ was delivered by syringe pump over $1 \mathrm{~h}$. The formation of transient purple color followed by light green color was observed during the addition of oxone solution. After stirring for another $1 \mathrm{~h}$, aqueous $\mathrm{Na}_{2}$ EDTA solution $(5 \mathrm{~mL})$ and water $(20 \mathrm{~mL})$ were added to reaction mixture and the mixture was extracted with chloroform $(3 \times 20 \mathrm{~mL})$. The combined organic layers were dried $\left(\mathrm{Na}_{2} \mathrm{SO}_{4}\right)$, filtered and concentrated to give a gummy solid. Compound 15 was determined to be the major product by ${ }^{1} \mathrm{HNMR}$ analysis, and the yield of 15 was measured to be (17\%) with 1,3,5-tribromobenzene as an internal standard by integrating peaks at 7.60 (15) and 6.78 (1,3,5-tribromobenzene) ppm. In a separate experiment compound $\mathbf{1 5}$ was isolated by reverse phase HPLC for characterization purposes. 


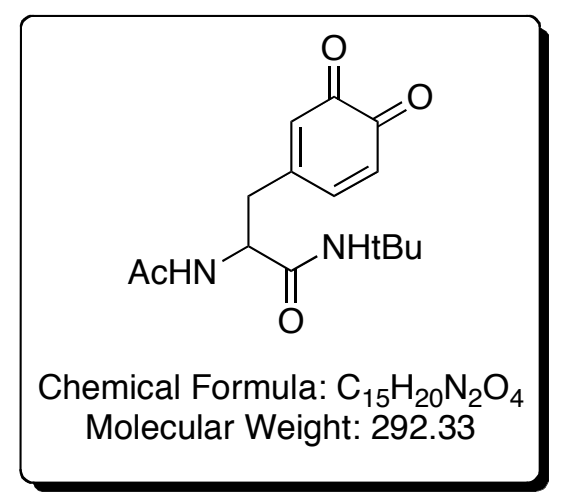

(S)-2-Acetamido-N-tert-butyl-3-(3,4-dioxocyclohexa-1,5-dienyl)propanamide

(15).

HPLC column Zorbax XDB-C18,21.2 X 150 mm, 5 micron equipped with guard column Zorbax XDB-C18, $21.2 \mathrm{~mm}, 5$ micron, flow rate $=20 \mathrm{~mL} / \mathrm{min}$, gradient elution $0-3 \mathrm{~min}$ 5\% MeCN: $\mathrm{H}_{2} \mathrm{O}, 3-15 \min 5-95 \% \mathrm{MeCN}: \mathrm{H}_{2} \mathrm{O}, \mathrm{T}_{\mathrm{R}}=9.2 \mathrm{~min} ;{ }^{1} \mathrm{H} \mathrm{NMR}\left(\mathrm{CDCl}_{3}\right) 6.79(\mathrm{~d}, J$ $=9.7 \mathrm{~Hz}, 1 \mathrm{H}), 6.70(\mathrm{dd}, J=9.7,2.4 \mathrm{~Hz}, 1 \mathrm{H}), 6.54(\mathrm{~d}, J=2.4,1 \mathrm{H}), 6.30(\mathrm{~d}, J=7.2 \mathrm{~Hz}$, 1H), 5.85 (brs, 1H), $4.46(\mathrm{~m}, 1 \mathrm{H}), 2.91$ (dd, $J=12.5,3.6 \mathrm{~Hz}, 1 \mathrm{H}), 2.52$ (dd, $J=13.3,9.3$ $\mathrm{Hz}, 1 \mathrm{H}), 1.92(\mathrm{~s}, 3 \mathrm{H}), 1.32(\mathrm{~s}, 9 \mathrm{H}) ;{ }^{13} \mathrm{C} \mathrm{NMR}\left(\mathrm{CDCl}_{3}\right)$ 187.3, 187.2, 170.2, 169.2, 144.8, 136.7, 136.5, 134.0, 52.5, 51.8, 34.4, 28.6, 23.0; IR (thin film) 3291, 3079, 2970,1655, 1540, 1456, 1366, 1291, 1224, 1082, 913, $731 \mathrm{~cm}^{-1}$; LRMS (ESMS) calcd for $\mathrm{C}_{15} \mathrm{H}_{21} \mathrm{~N}_{2} \mathrm{O}_{4}(\mathrm{M}+\mathrm{H})^{+}:$293, found: 293.

\section{Oxidation studies of tryptophan substrate 6 with $\left[\mathrm{Fe}^{\mathrm{II}}(\mathrm{N} 4 \mathrm{Py}) \mathrm{CH}_{3} \mathrm{CN}\right]\left(\mathrm{ClO}_{4}\right)_{2}(8)$ and} oxone. An orange-red color mixture of $6(200 \mathrm{mg}, 663 \mu \mathrm{mol})$, $\left[\mathrm{Fe}^{\mathrm{II}}(\mathrm{N} 4 \mathrm{Py}) \mathrm{CH}_{3} \mathrm{CN}\right]\left(\mathrm{ClO}_{4}\right)_{2}(4.4 \mathrm{mg}, 6.6 \mu \mathrm{mol})$, and $\mathrm{H}_{2} \mathrm{O}-\mathrm{CH}_{3} \mathrm{CN}(40 \mathrm{~mL}, 3: 1)$ was stirred under open air at rt. After stirring for $5 \mathrm{~min}$, oxone $(1.22 \mathrm{~g}, 1.99 \mathrm{mmol})$ in $10 \mathrm{~mL}$ of $\mathrm{H}_{2} \mathrm{O}$ was delivered by syringe pump over $1 \mathrm{~h}$. The formation of a transient purple color was observed followed by a dark brown color. After stirring for $1 \mathrm{~h}$, aqueous $\mathrm{Na}_{2}$ EDTA solution $(50 \mathrm{~mL})$ and water $(200 \mathrm{~mL})$ were added to reaction mixture and the aqueous 
layer was extracted with chloroform $(3 \times 200 \mathrm{~mL})$. The combined organic layers were dried $\left(\mathrm{Na}_{2} \mathrm{SO}_{4}\right)$, filtered and concentrated to give crude $(127 \mathrm{mg})$ as a dark brown gummy liquid. Compound $\mathbf{1 6}$ was determined to be the major product by ${ }^{1} \mathrm{HNMR}$ analysis of the crude reaction mixture, and the yield of $\mathbf{1 6}(45 \mathrm{mg}, 19 \%)$ was measured based on isolated yield from silica gel chromatography (30-40\% EtOAc:hexanes). The structure of $\mathbf{1 6}$ is supported by the following data:

${ }^{1} H$ NMR spectrum shows

a) two doublets and two triplets in the aromatic region, indicating the presence of a disubstituted aromatic ring b) resonances at 7.36 and $6.48 \mathrm{ppm}$ are lost upon addition of $\mathrm{CD}_{3} \mathrm{OD}$, indicating that only two exchangeable protons are present c) the $\alpha-\mathrm{CH}$, which has a resonance at $4.75 \mathrm{ppm}$, is only coupled to $1 \mathrm{CH}$ of the adjacent $\mathrm{CH}_{2}$ unit, which indicates that free rotation is not possible and a ring has formed; also this $\alpha-\mathrm{CH}$ proton is not coupled to an adjacent $\mathrm{NH}$ as observed with other products

${ }^{13}$ C NMR and DEPT data show

a) three carbonyl resonances at 172.6, 172.2 and $171.4 \mathrm{ppm}$

b) a tetrasubstituted carbon at $77.6 \mathrm{ppm}$, consistent with the tertiary alcohol

c) one $\mathrm{CH}_{2}$ unit (36.7 ppm) and one $\mathrm{CH}$ unit (57.8 ppm) 


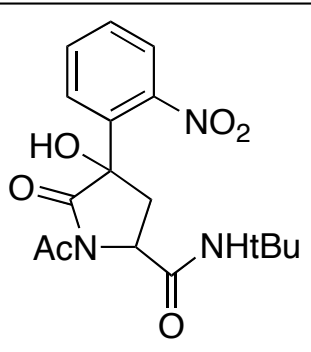

Chemical Formula: $\mathrm{C}_{17} \mathrm{H}_{21} \mathrm{~N}_{3} \mathrm{O}_{6}$ Molecular Weight: 363.37

1-Acetyl- $N$-tert-butyl-4-hydroxy-4-(2-nitrophenyl)-5-oxopyrolidine-2-carboxamide

(16). ${ }^{1} \mathrm{H} \mathrm{NMR}\left(\mathrm{CDCl}_{3}\right) \delta 8.31(\mathrm{dd}, J=7.9,1.2 \mathrm{~Hz}, 1 \mathrm{H}), 8.05(\mathrm{dd}, J=8.2,1.2 \mathrm{~Hz}, 1 \mathrm{H})$, $7.72(\mathrm{dt}, J=7.9,1.2 \mathrm{~Hz}, 1 \mathrm{H}), 7.50$ (dt, $J=8.2,1.5 \mathrm{~Hz}, 1 \mathrm{H}), 7.36$ (brs, 1H), 6.48 (brs, 1H), $4.75(\mathrm{~d}, J=9.1 \mathrm{~Hz}, 1 \mathrm{H}), 2.90(\mathrm{dd}, J=14.3,9.1 \mathrm{~Hz}, 1 \mathrm{H}), 2.53(\mathrm{~s}, 3 \mathrm{H}), 2.31(\mathrm{~d}, J=$ 14.3 Hz, 1H), 1.37 (s, 9H); ${ }^{13} \mathrm{C} \mathrm{NMR}\left(\mathrm{CDCl}_{3}\right)$ 172.6, 172.2, 171.4, 146.8, 134.8, 134.0, 130.0, 129.2, 125.3, 77.6, 57.8, 52.5, 36.7, 28.3, 24.8; IR (thin film) 3582, 3354, 2970, 2359, 1757, 1713, 1652, 1529, 1344, $1269 \mathrm{~cm}^{-1}$; LRMS (ESMS) calcd for $\mathrm{C}_{17} \mathrm{H}_{22} \mathrm{~N}_{3} \mathrm{O}_{6}$ $(\mathrm{M}+\mathrm{H})^{+}: 364$, found: 364 .

Oxidation studies of methionine substrate 7 with $\left[\mathrm{Fe}^{\mathrm{II}}(\mathrm{N} 4 \mathrm{Py}) \mathrm{CH}_{3} \mathrm{CN}\right]\left(\mathrm{ClO}_{4}\right)_{2}(8)$ and oxone. An orange-red color mixture of $7(50 \mathrm{mg}, 203 \mu \mathrm{mol}),\left[\mathrm{Fe}^{\mathrm{II}}(\mathrm{N} 4 \mathrm{Py}) \mathrm{CH}_{3} \mathrm{CN}\right]\left(\mathrm{ClO}_{4}\right)_{2}$ (1.34 mg, $2.03 \mu \mathrm{mol}$ ), and $\mathrm{H}_{2} \mathrm{O}: \mathrm{CH}_{3} \mathrm{CN}(10 \mathrm{~mL}, 3: 1)$ was stirred under open air at $\mathrm{rt}$. After stirring for $5 \mathrm{~min}$, oxone $(370 \mathrm{mg}, 610 \mu \mathrm{mol})$ in $2.5 \mathrm{~mL}$ of water was delivered by syringe pump over $1 \mathrm{~h}$. The formation of transient purple color followed by green color solution was observed during the addition of oxone solution. After stirring for another 1 h, $10 \mathrm{~mL}$ of aqueous $\mathrm{Na}_{2}$ EDTA solution was added to reaction mixture and reaction mixture was extracted with chloroform $(3 \times 50 \mathrm{~mL})$. The combined organic layers were dried $\left(\mathrm{Na}_{2} \mathrm{SO}_{4}\right)$, and concentrated to give brown color crude $(65 \mathrm{mg})$ as a gummy solid. 
Crude product was purified by column chromatography ( $\mathrm{MeOH}-\mathrm{CHCl}_{3}$ gradient system) to give sulfone $\mathbf{1 6}$ (55 $\mathrm{mg}, 97 \%$ ) as a white solid.

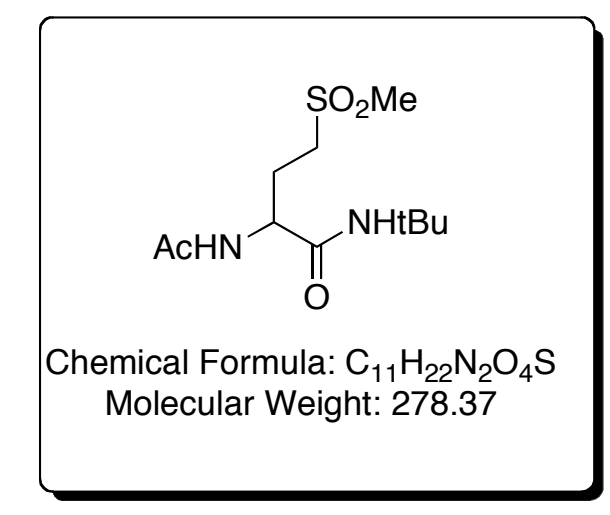

(S)-2-Acetamido-N-tert-butyl-4-(methylsulfonyl)butanamide (17). ${ }^{1} \mathrm{H}$ NMR $\left(\mathrm{CDCl}_{3}\right)$ $\delta 6.58(\mathrm{~d}, J=7 \mathrm{~Hz}, 1 \mathrm{H}), 6.31(\mathrm{~s}, 1 \mathrm{H}), 4.52(\mathrm{dd}, J=13.8,6.4 \mathrm{~Hz}, 1 \mathrm{H}), 3.25(\mathrm{~m}, 1 \mathrm{H}), 3.07$ $(\mathrm{m}, 1 \mathrm{H}), 2.97(\mathrm{~s}, 3 \mathrm{H}), 2.19(\mathrm{~m}, 2 \mathrm{H}), 2.00(\mathrm{~s}, 3 \mathrm{H}), 1.33(\mathrm{~s}, 9 \mathrm{H}) ;{ }^{13} \mathrm{C} \mathrm{NMR}\left(\mathrm{CDCl}_{3}\right) \delta$ $170.5,169.2,51.6,51.4,51.2,40.6,28.5,26.2,23.1$; IR (thin film) 3286, 3079, 2964, $1651,1555,1455,1392,1365,1301,1127,1019,800 \mathrm{~cm}^{-1}$; LRMS (ESMS) calcd for $\mathrm{C}_{11} \mathrm{H}_{22} \mathrm{~N}_{2} \mathrm{O}_{4} \mathrm{SNa}(\mathrm{M}+\mathrm{Na})^{+}:$301, found: 301. 
Part C. Kinetic Studies.

Reactions of the species $\left[\mathrm{Fe}^{\mathrm{IV}}(\mathrm{O})(\mathrm{N} 4 \mathrm{Py})\right]^{2+}$ with amino acid substrates 1-7 were conducted at $25{ }^{\circ} \mathrm{C}$ under pseudo-first-order conditions. Rate constants represent the average of at least three runs. The reactions were monitored using a UV-vis spectrophotometer and were performed using the following standard procedure. A $2 \mathrm{mM}$ solution of $\left[\mathrm{Fe}^{\mathrm{II}}(\mathrm{N} 4 \mathrm{Py})(\mathrm{MeCN})\right]\left(\mathrm{ClO}_{4}\right)_{2}$ in 3:1 $\mathrm{H}_{2} \mathrm{O}: \mathrm{MeCN}(1.0 \mathrm{~mL}, 20 \mu \mathrm{mol})$ was treated with a solution of oxone in $\mathrm{H}_{2} \mathrm{O}(100 \mu \mathrm{L}, 20 \mu \mathrm{mol}, 1$ equiv, $0.2 \mathrm{M})$. The solution turned from red to green and was aged for $10 \mathrm{~min}$ to allow for generation of $\left[\mathrm{Fe}^{\mathrm{IV}}(\mathrm{O})(\mathrm{N} 4 \mathrm{Py})\right]^{2+}$ to reach completion, as judged by maximization of absorbance at 680 $\mathrm{nm}$ and disappearance of the absorption band at $450 \mathrm{~nm}$, which corresponds with the $\mathrm{Fe}^{\mathrm{II}}$ species. Next, the green solution of $\left[\mathrm{Fe}^{\mathrm{IV}}(\mathrm{O})(\mathrm{N} 4 \mathrm{Py})\right]^{2+}$ was treated a solution of amino acid in 1:3 $\mathrm{H}_{2} \mathrm{O}: \mathrm{MeCN}(900 \mu \mathrm{L}, 200 \mu \mathrm{mol}, 10$ equiv, $0.2 \mathrm{M})$. After mixing (10 sec), the reaction was monitored by UV-vis spectroscopy (Figure S2). The absorbance traces for the decomposition of $\left[\mathrm{Fe}^{\mathrm{IV}}(\mathrm{O})(\mathrm{N} 4 \mathrm{Py})\right]^{2+}(\lambda=680 \mathrm{~nm})$ showed first-order decay and fit well to the single exponential equation $\left.\left[\mathrm{A}=\Delta \mathrm{A}\left(1-\mathrm{e}^{\mathrm{kt}}\right)+\mathrm{A}_{0}\right)\right]$ for substrates $\mathbf{1}, \mathbf{6}$ and $\mathbf{7}$ (Table 1, Figures S2-S5). With substrate 5, decomposition of the $\left[\mathrm{Fe}^{\mathrm{IV}}(\mathrm{O})(\mathrm{N} 4 \mathrm{Py})\right]^{2+}$ was complete immediately upon mixing $(10 \mathrm{sec})$, as judged by disappearance of the absorption band at $680 \mathrm{~nm}$. With substrate 4, decay of the signal at $680 \mathrm{~nm}$ could not be fit satisfactorily to the first-order rate equation, but qualitatively decay was slower than with 1. Substrates 2 and 3 did not cause absorbance at $680 \mathrm{~nm}$ to decay faster than a control experiment in which no substrate was added. 
Figure S2. Spectral changes upon mixing 6 (10 equiv) with a solution of $\left[\mathrm{Fe}^{\mathrm{IV}}(\mathrm{O})(\mathrm{N} 4 \mathrm{Py})\right]^{2+}$ in $1: 1 \mathrm{H}_{2} \mathrm{O}: \mathrm{MeCN}$ (final concentration $=1 \mathrm{mM}$ ) at $25{ }^{\circ} \mathrm{C}$.

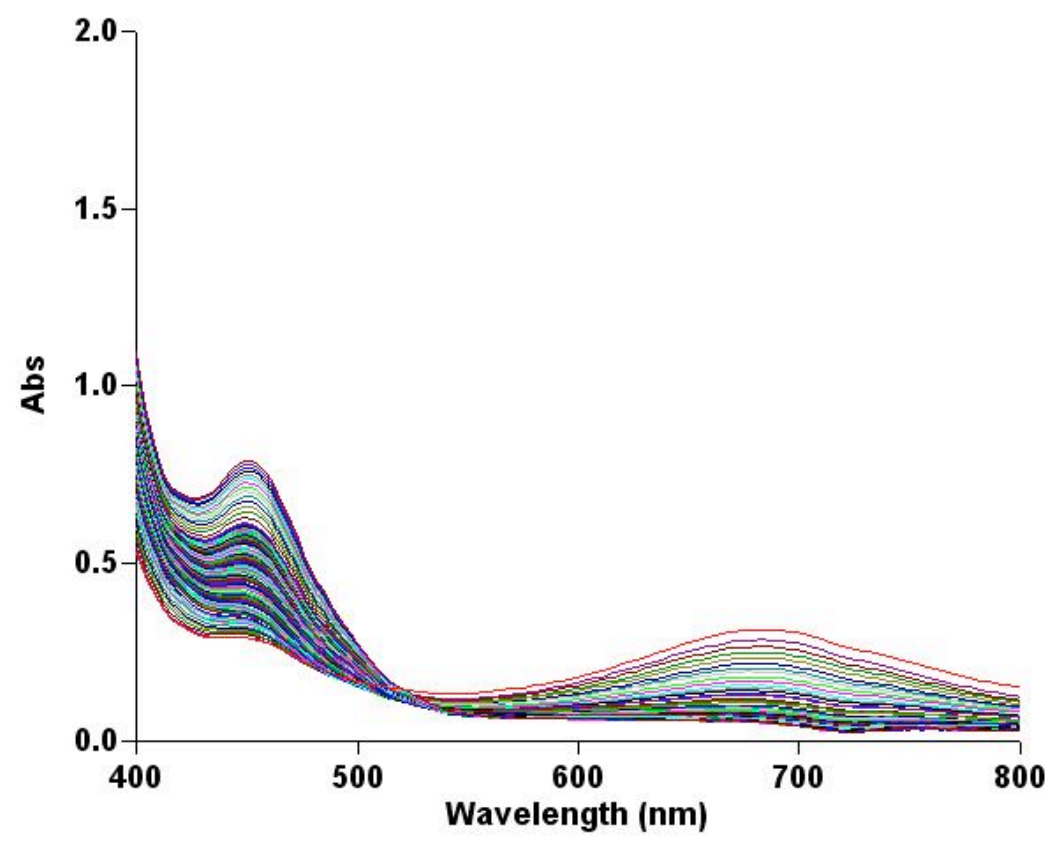

Figure S3. Time course of the decay of $\left[\mathrm{Fe}^{\mathrm{IV}}(\mathrm{O})(\mathrm{N} 4 \mathrm{Py})\right]^{2+}(1 \mathrm{mM})$ upon treatment with substrate 6 (10 equiv) in 1:1 $\mathrm{H}_{2} \mathrm{O}: \mathrm{MeCN}$ at $25{ }^{\circ} \mathrm{C}$ (absorbance at $680 \mathrm{~nm}=$ red line, calculated fit $=$ blue line, $\left.\mathrm{k}_{\mathrm{obs}}=17.0(5) \times 10^{-3} \mathrm{~s}^{-1}\right)$.

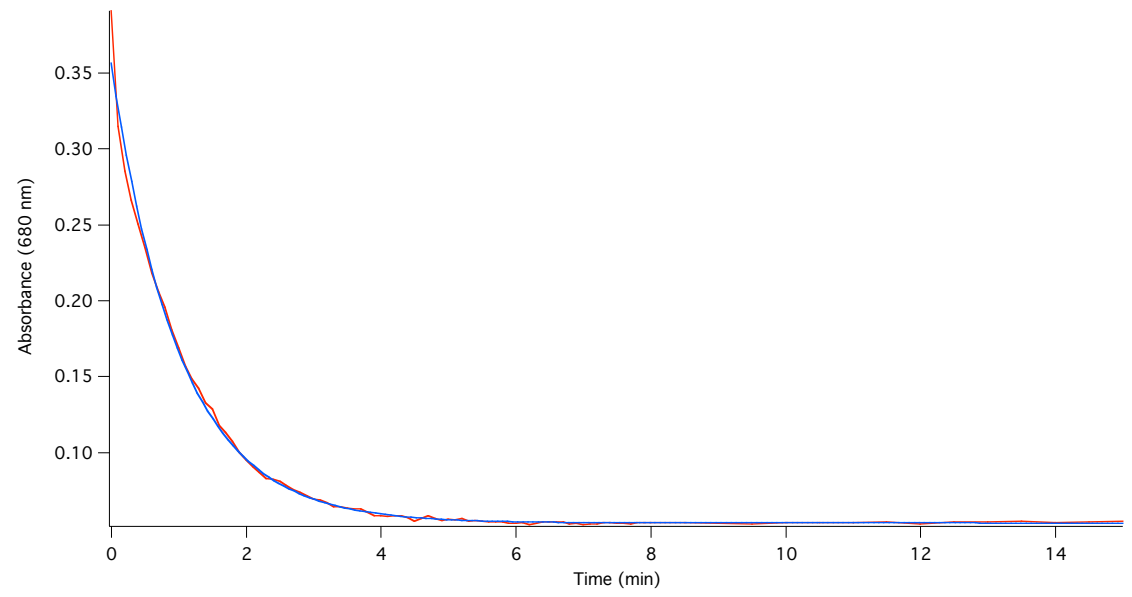


Figure S4. Time course of the decay of $\left[\mathrm{Fe}^{\mathrm{IV}}(\mathrm{O})(\mathrm{N} 4 \mathrm{Py})\right]^{2+}(1 \mathrm{mM})$ upon treatment with substrate 7 (10 equiv) in 1:1 $\mathrm{H}_{2} \mathrm{O}: \mathrm{MeCN}$ at $25{ }^{\circ} \mathrm{C}$ (absorbance at $680 \mathrm{~nm}=$ red line, calculated fit $=$ blue line, $\left.\mathrm{k}_{\mathrm{obs}}=3.15(8) \times 10^{-3} \mathrm{~s}^{-1}\right)$.

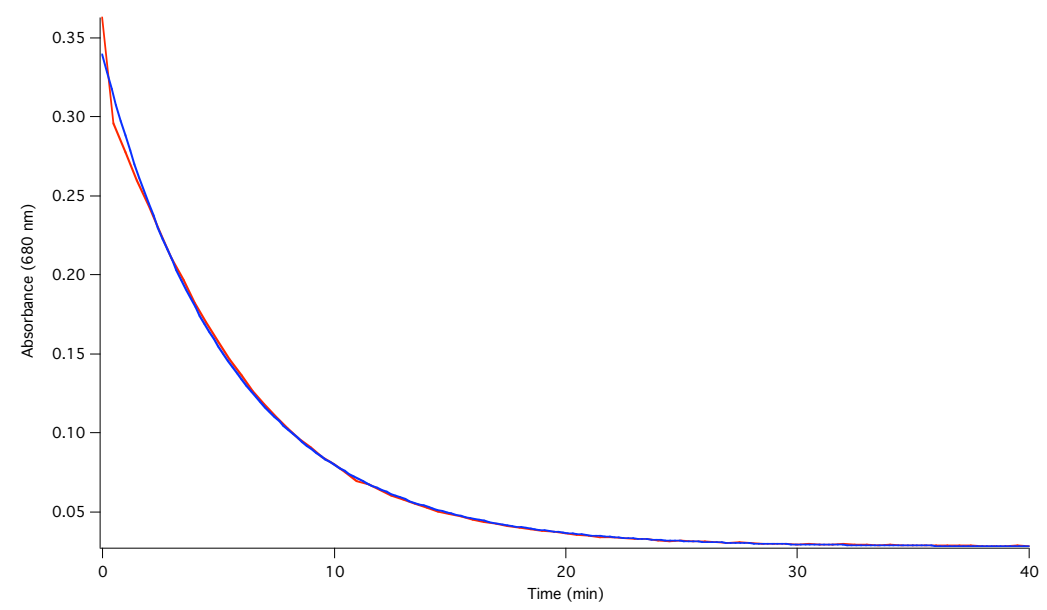

Figure S5. Time course of the decay of $\left[\mathrm{Fe}^{\mathrm{IV}}(\mathrm{O})(\mathrm{N} 4 \mathrm{Py})\right]^{2+}(1 \mathrm{mM})$ upon treatment with substrate 1 (10 equiv) in 1:1 $\mathrm{H}_{2} \mathrm{O}: \mathrm{MeCN}$ at $25{ }^{\circ} \mathrm{C}$ (absorbance at $680 \mathrm{~nm}=$ red line, calculated fit $=$ blue line, $\left.\mathrm{k}_{\mathrm{obs}}=5.8(2) \times 10^{-5} \mathrm{~s}^{-1}\right)$.

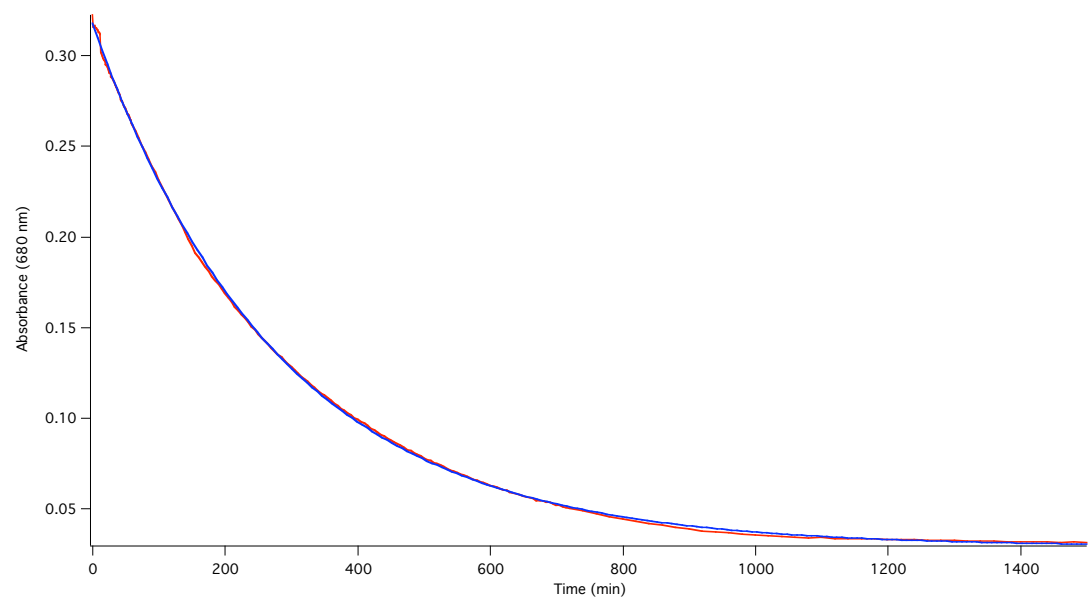


Figure S6. Time course of the decay of $\left[\mathrm{Fe}^{\mathrm{IV}}(\mathrm{O})(\mathrm{N} 4 \mathrm{Py})\right]^{2+}(1 \mathrm{mM})$ upon treatment with substrate $2,2-d_{2}-1$ (10 equiv) in 1:1 $\mathrm{H}_{2} \mathrm{O}: \mathrm{MeCN}$ at $25{ }^{\circ} \mathrm{C}$ (absorbance at $680 \mathrm{~nm}=$ red line, calculated fit $=$ blue line, $\left.\mathrm{k}_{\mathrm{obs}}=1.2(2) \times 10^{-5} \mathrm{~s}^{-1}\right)$.

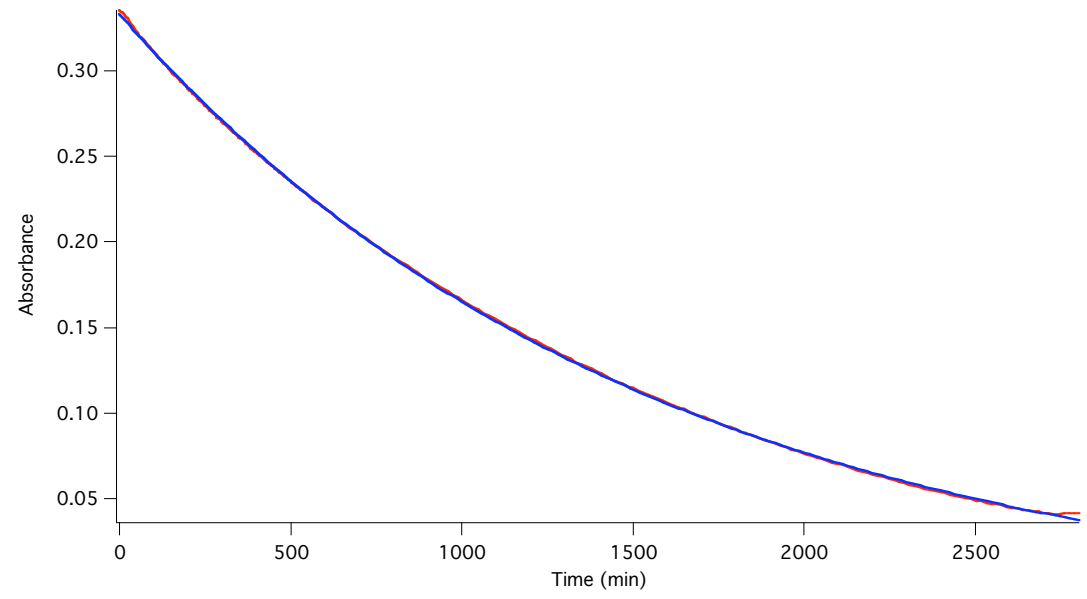

Figure S6. Time course of the decay of $\left[\mathrm{Fe}^{\mathrm{IV}}(\mathrm{O})(\mathrm{N} 4 \mathrm{Py})\right]^{2+}(1 \mathrm{mM})$ upon treatment with substrate 4 in 1:1 $\mathrm{H}_{2} \mathrm{O}: \mathrm{MeCN}$ at $25^{\circ} \mathrm{C}$ (absorbance at $680 \mathrm{~nm}=$ red line).

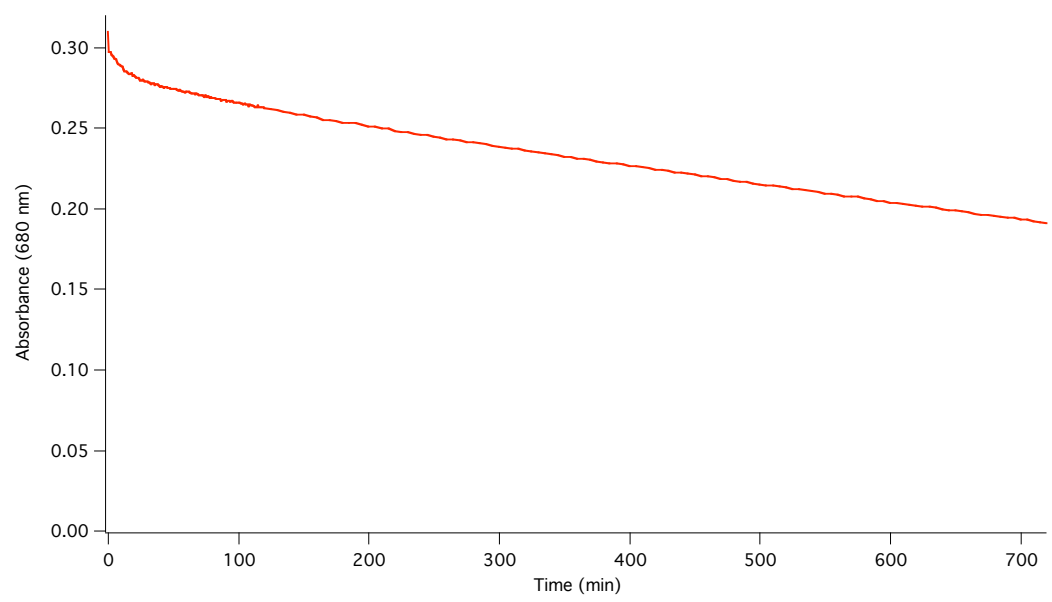




\section{Part D. References}

(1) Roelfes, G.; Lubben, M.; W. Leppard, S.; Schudde, E. P.; Hermant, R. M.; Hage, R.; Wilkinson, E. C.; Que, L., Jr.; Feringa, B. L. J. Mol. Catal. A: Chem. 1997, $117,223-227$.

(2) Lim, M. H.; Rohde, J.-U.; Stubna, A.; Bukowski, M. R.; Costas, M.; Ho, R. Y. N.; Munck, E.; Nam, W.; Que, L., Jr. Proc. Natl. Acad. Sci. U.S.A. 2003, 100, 3665-3670.

(3) Britovsek, G. J. P.; England, J.; White, A. J. P. Inorg. Chem. 2005, 44, $8125-8134$.

(4) Chenault, H. K.; Dahmer, J.; Whitesides, G. M. J. Am. Chem. Soc. 1989, $111,6354-64$.

(5) Brand, N.; Mailhot, G.; Bolte, M. Chemosphere 1997, 34, 2637-2648.

(6) Koenig, S.; Lohberger, S.; Ugi, I. Synthesis 1993, 1233-4. 
Part E. ${ }^{1} \mathrm{H}$ and ${ }^{13} \mathrm{C}$ NMR spectra for all new compounds

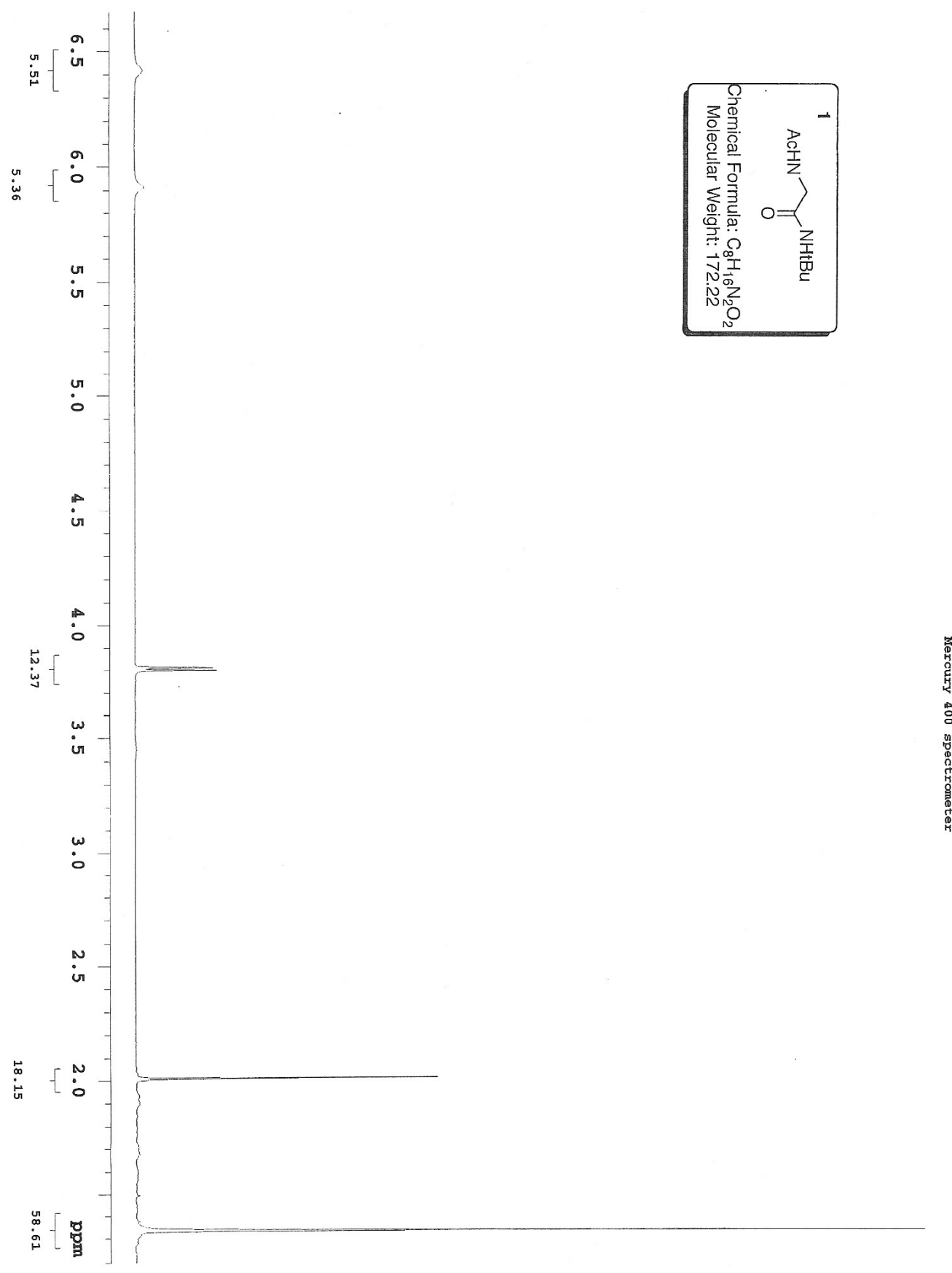


Supporting Information Ekkati, Kodanko*

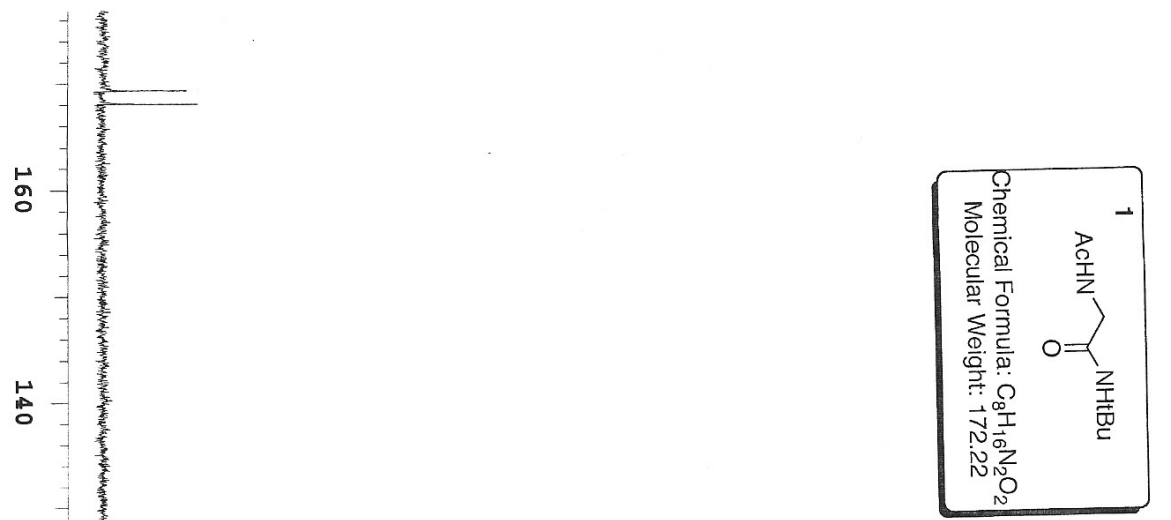


Supporting Information Ekkati, Kodanko*

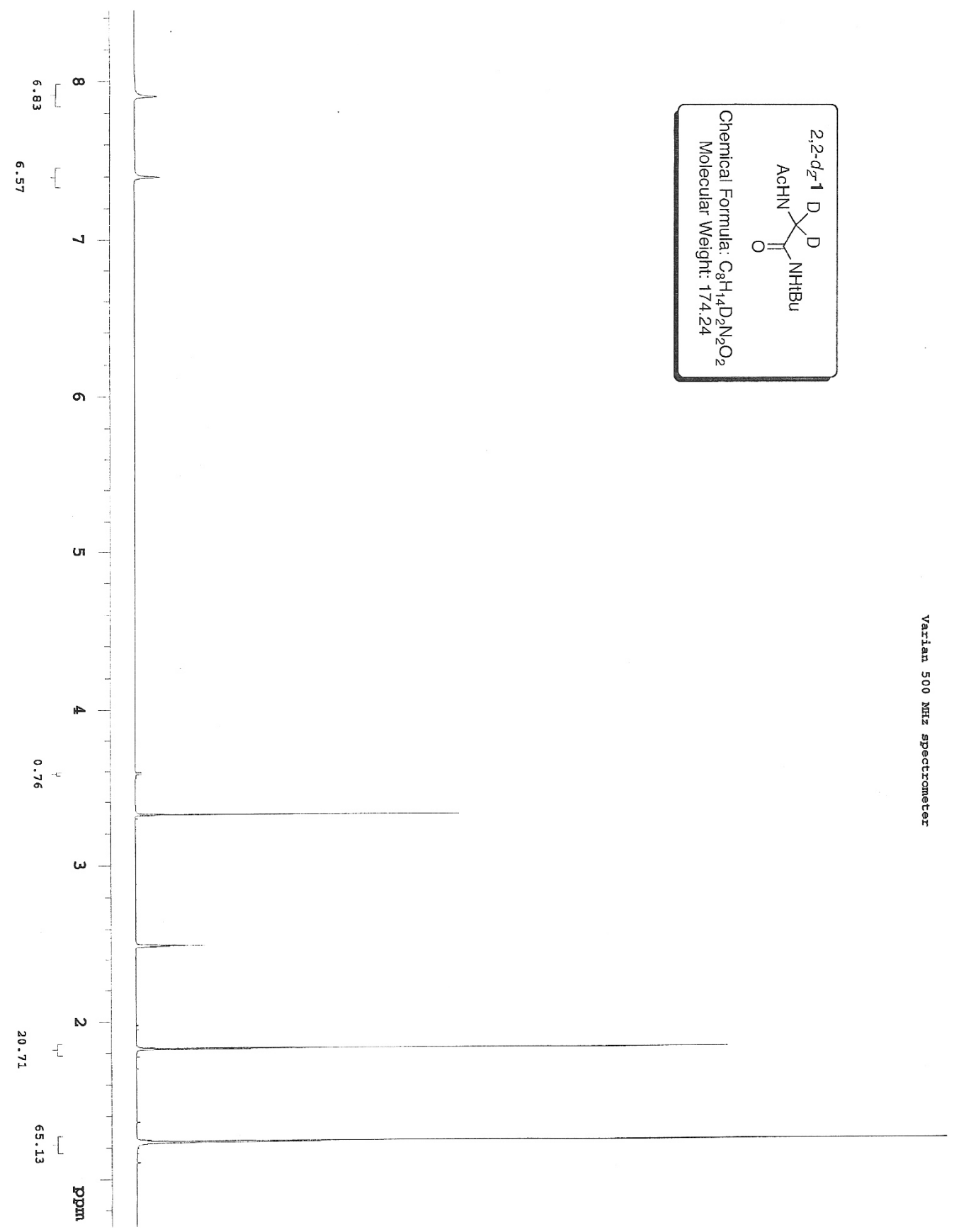


Supporting Information Ekkati, Kodanko*

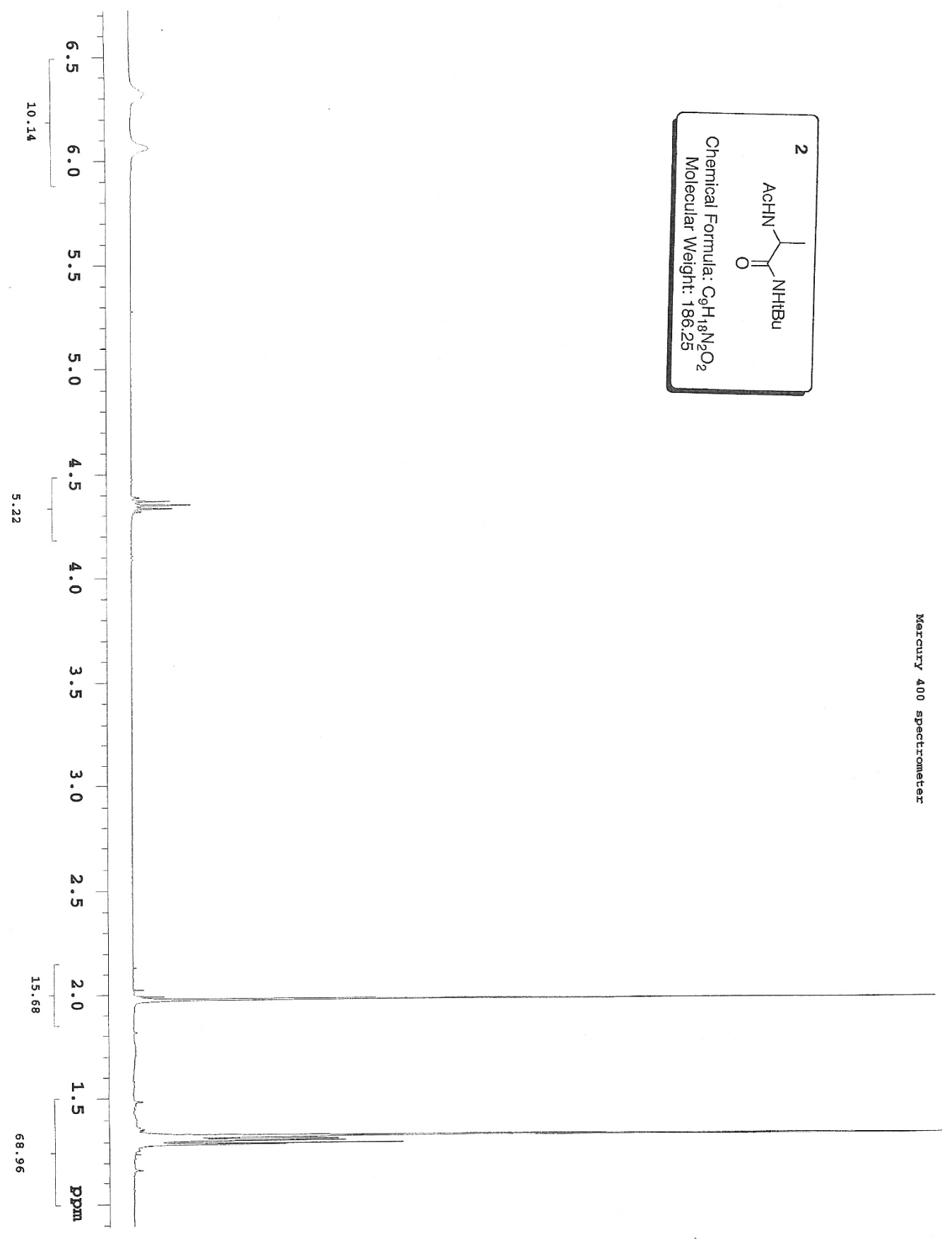


Supporting Information Ekkati, Kodanko*
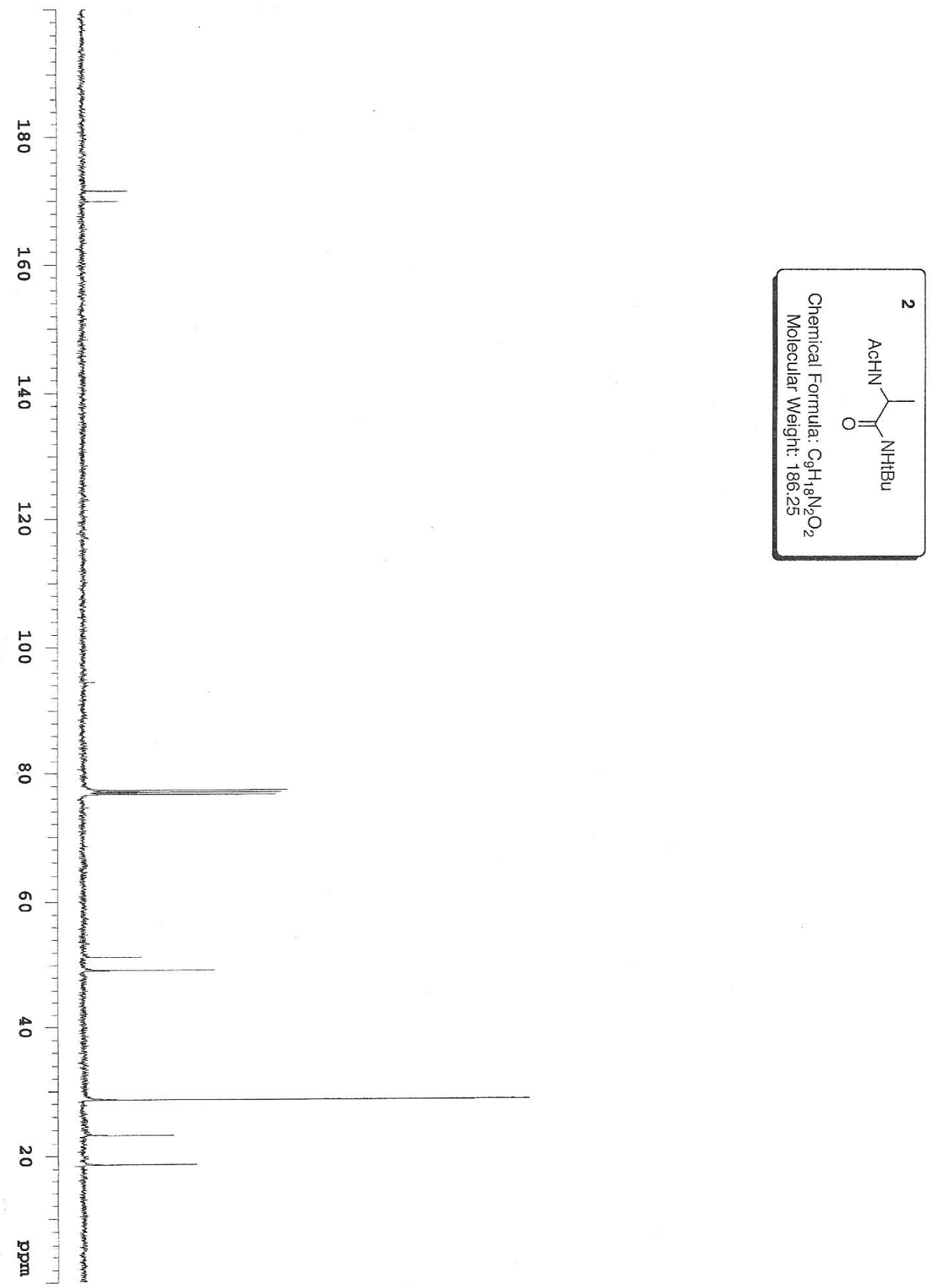


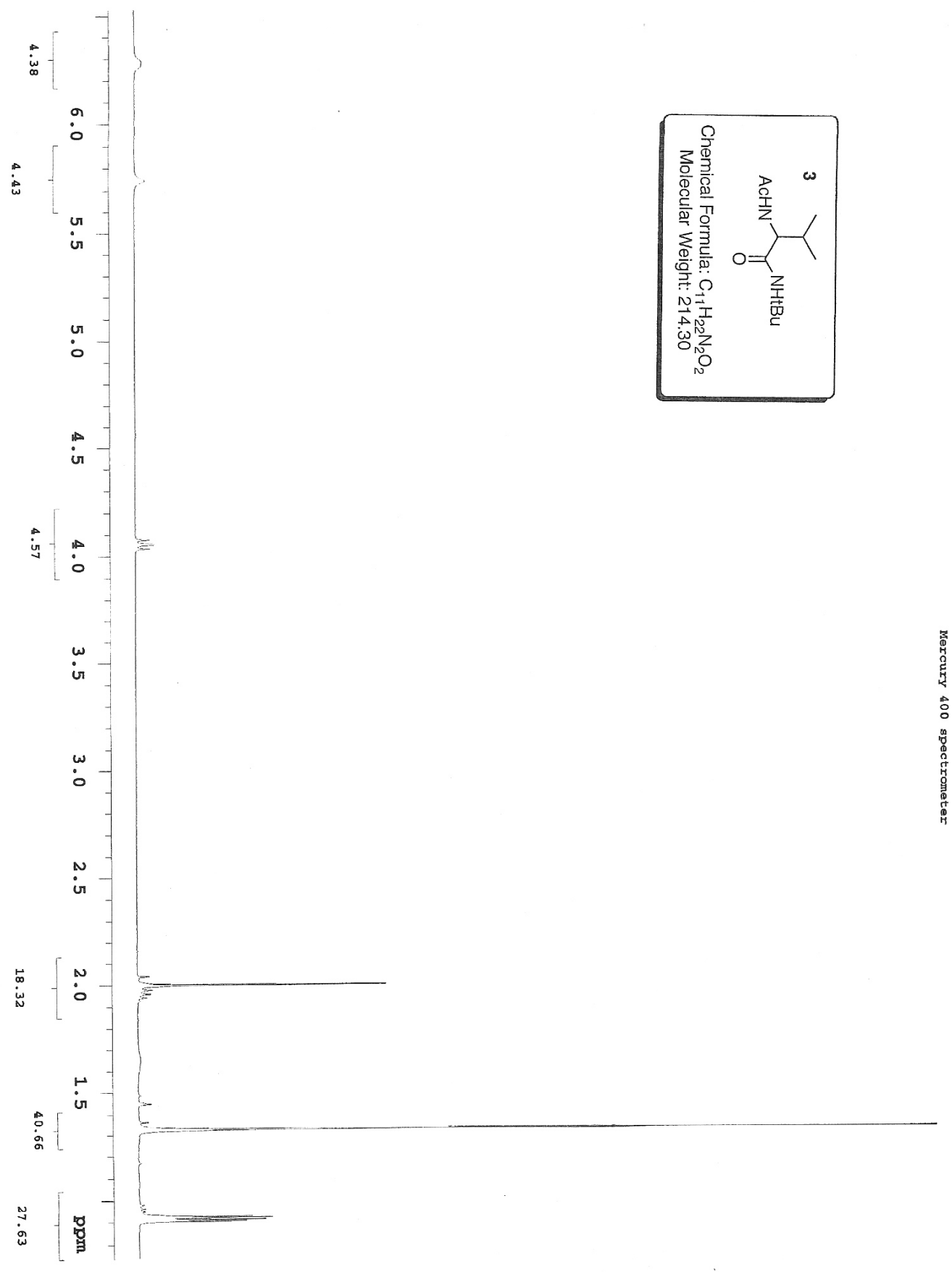


Supporting Information Ekkati, Kodanko*

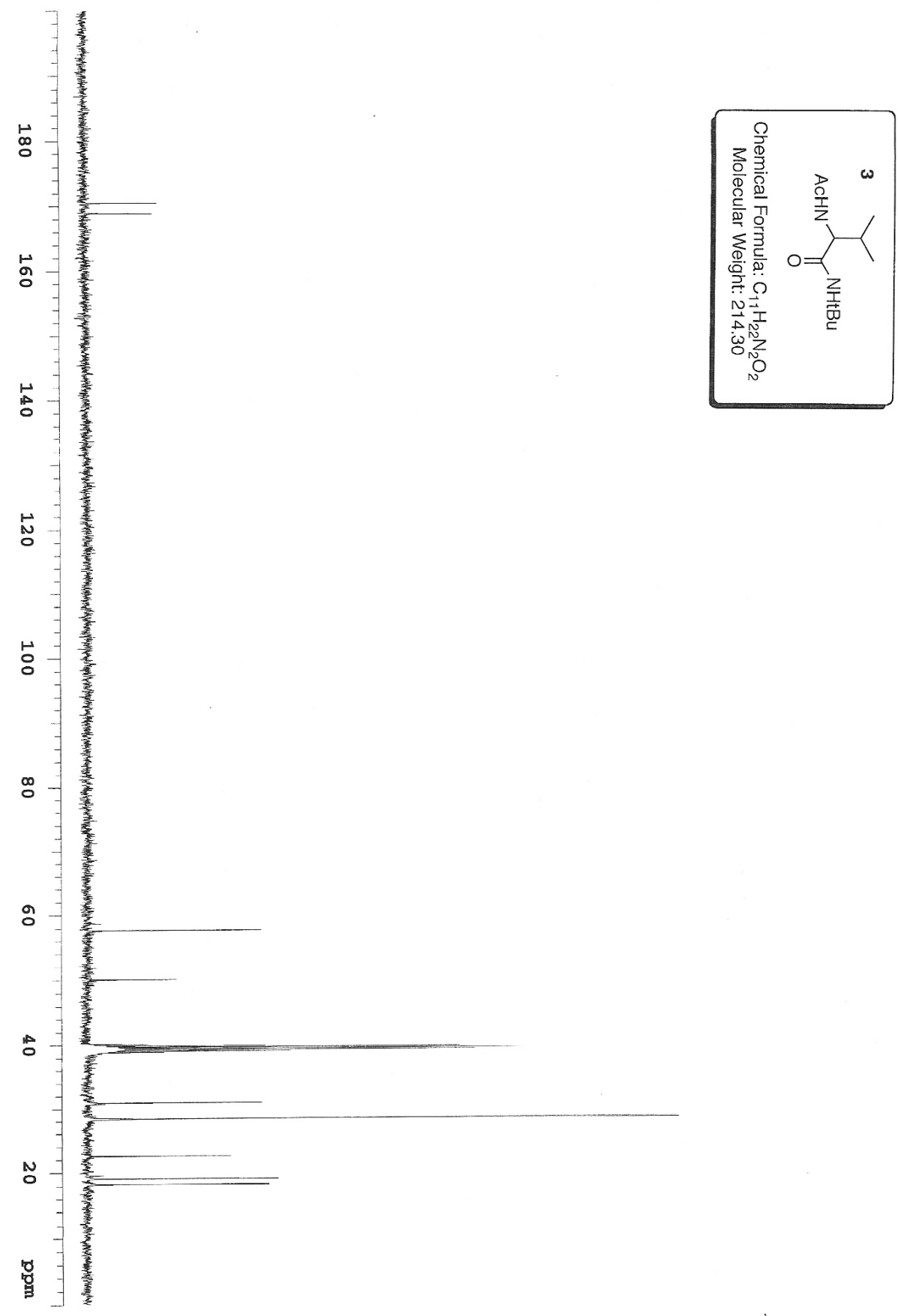




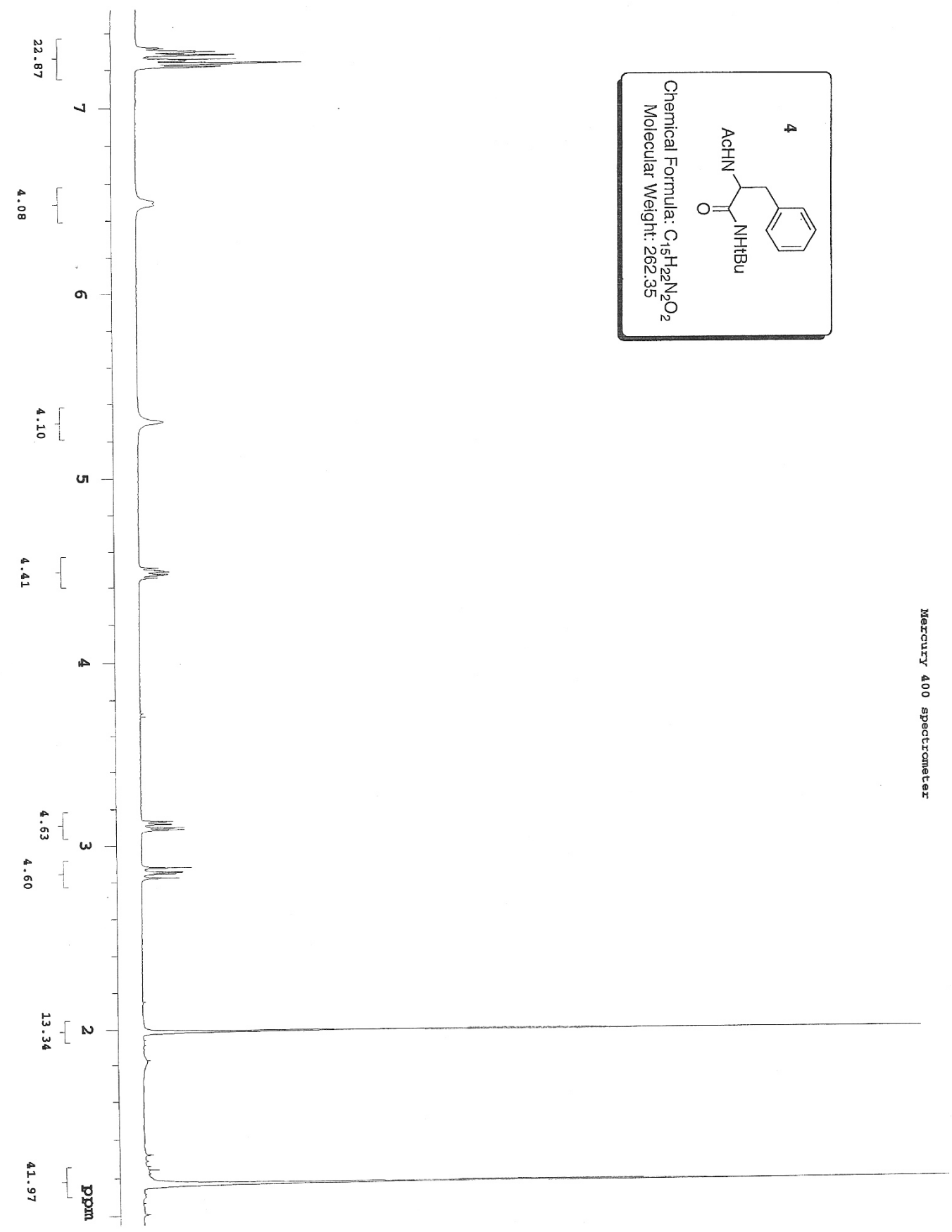



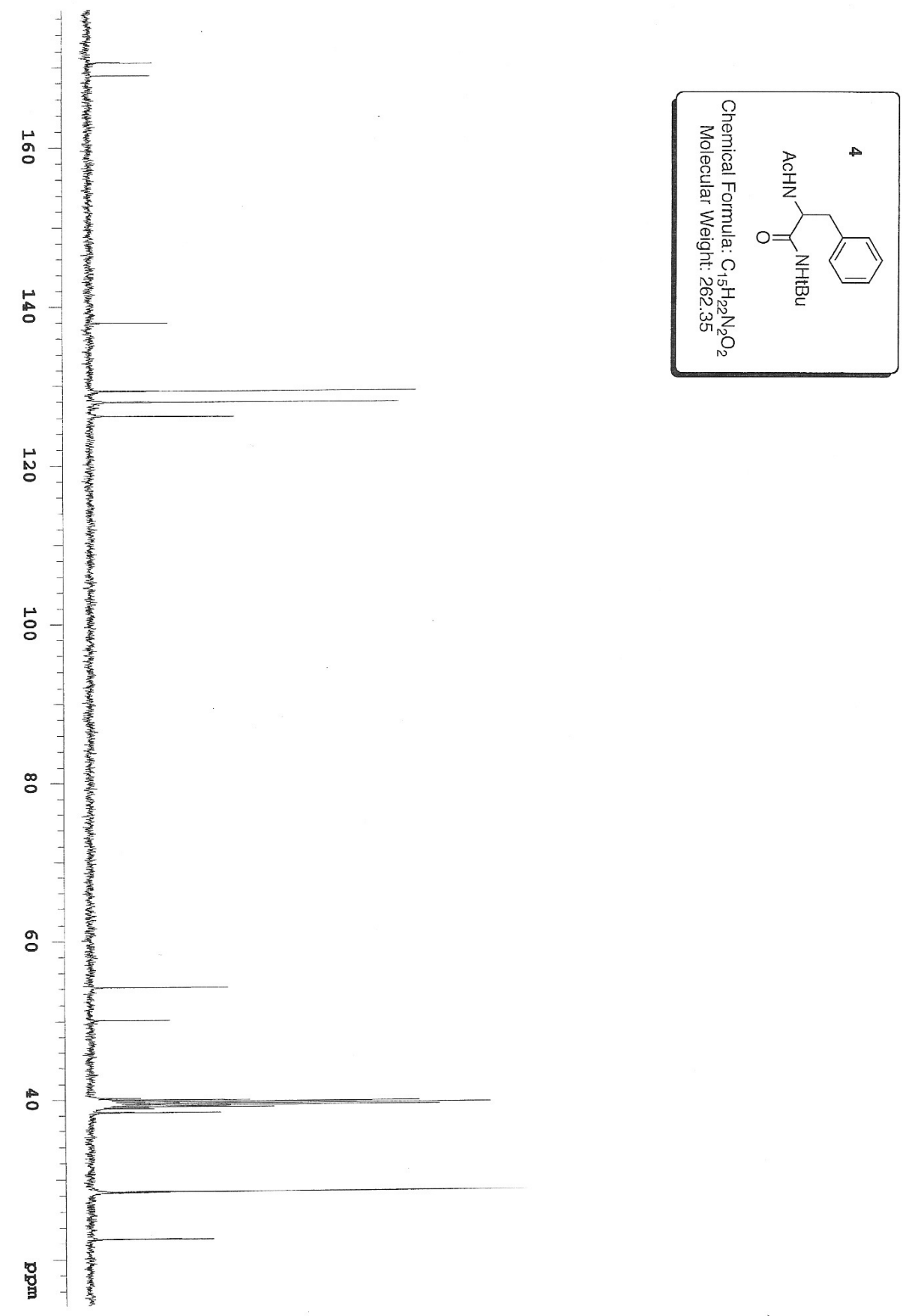


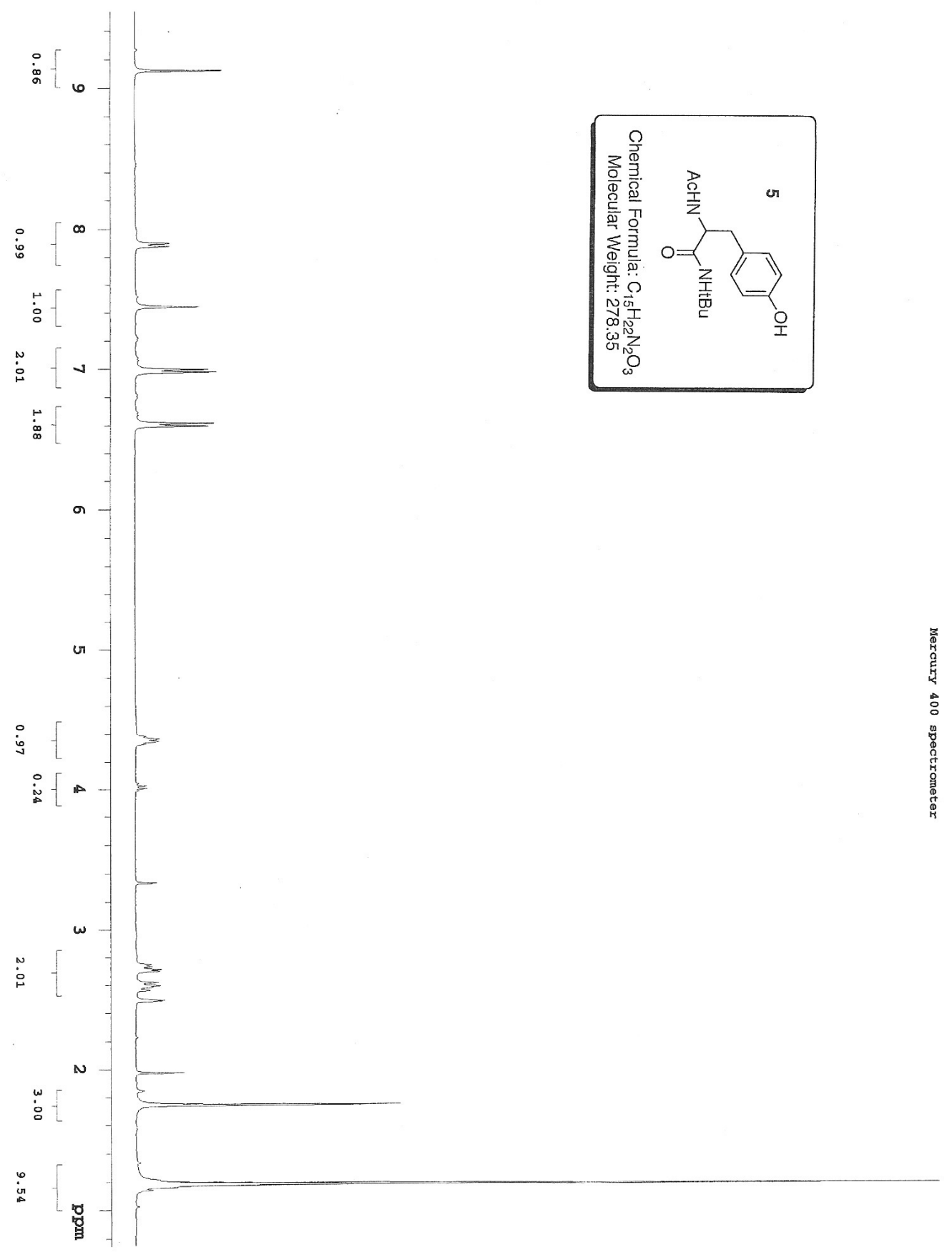



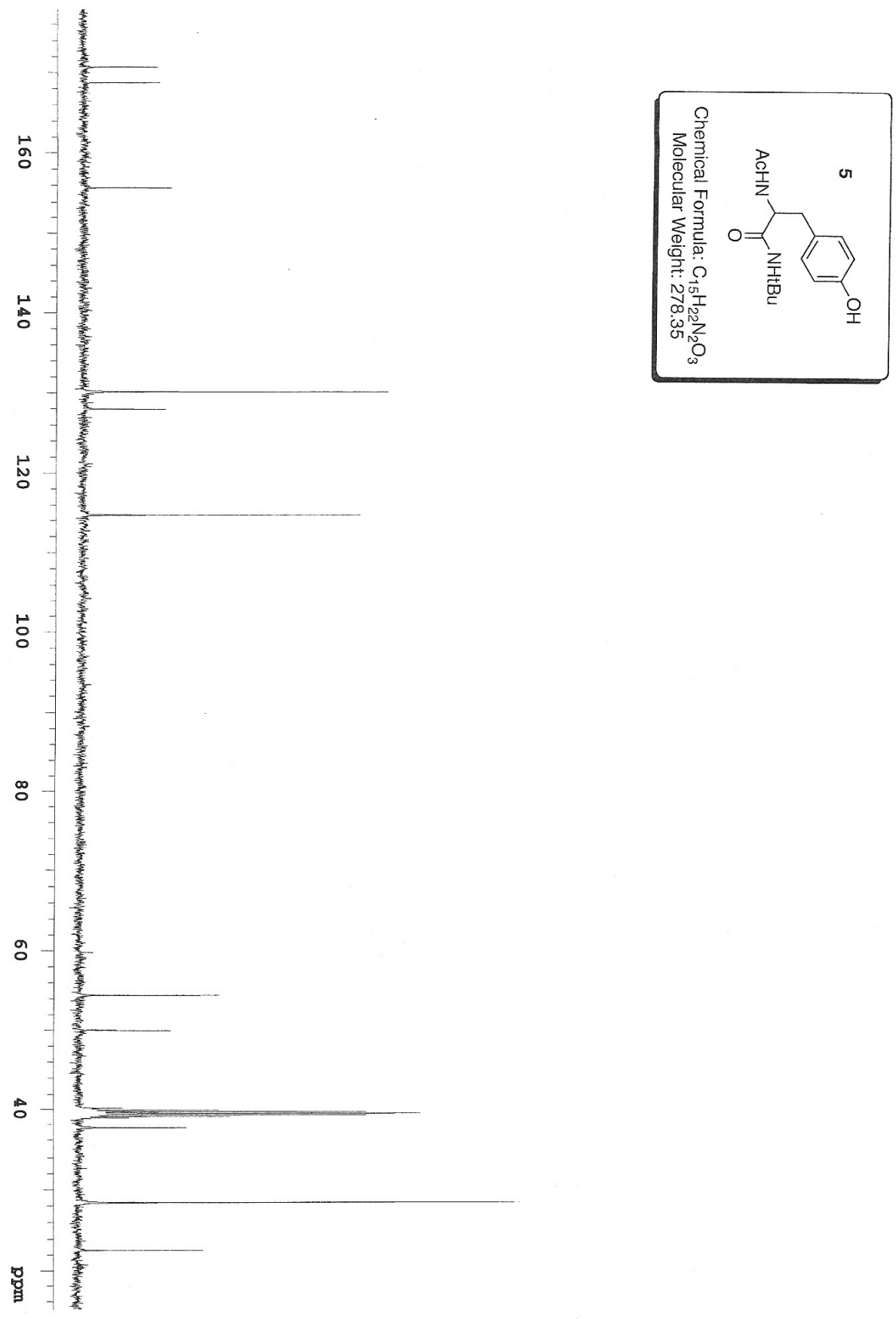


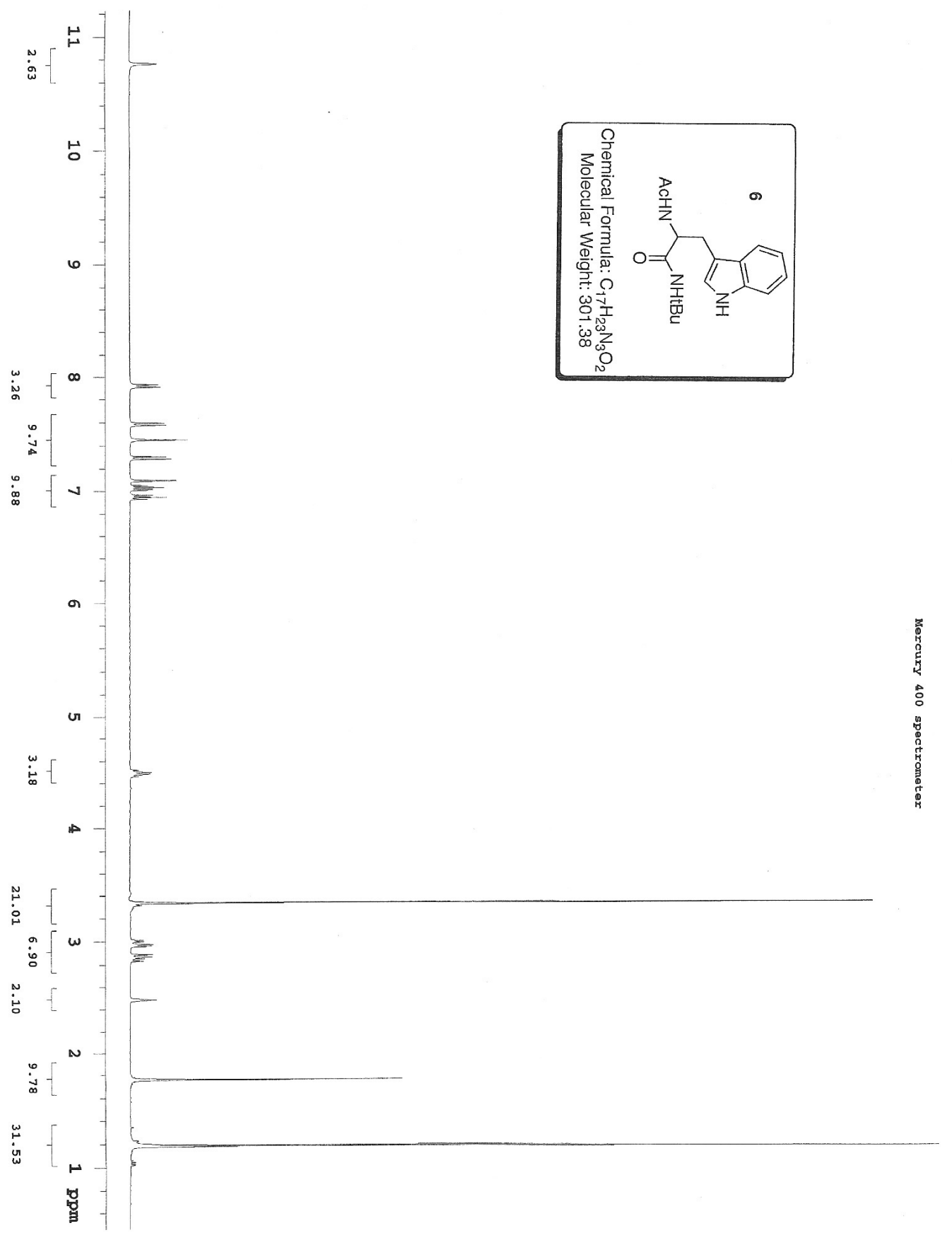




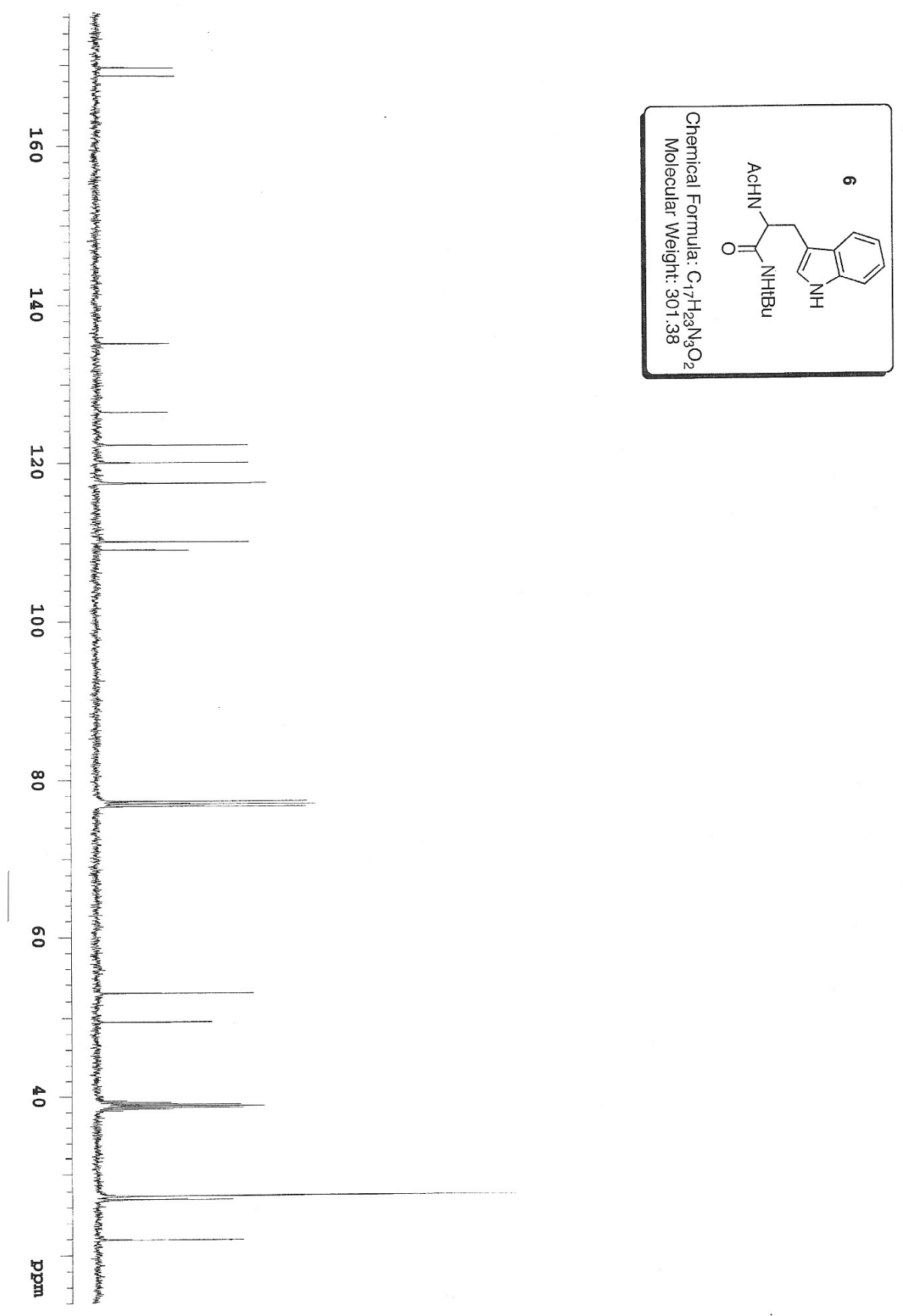




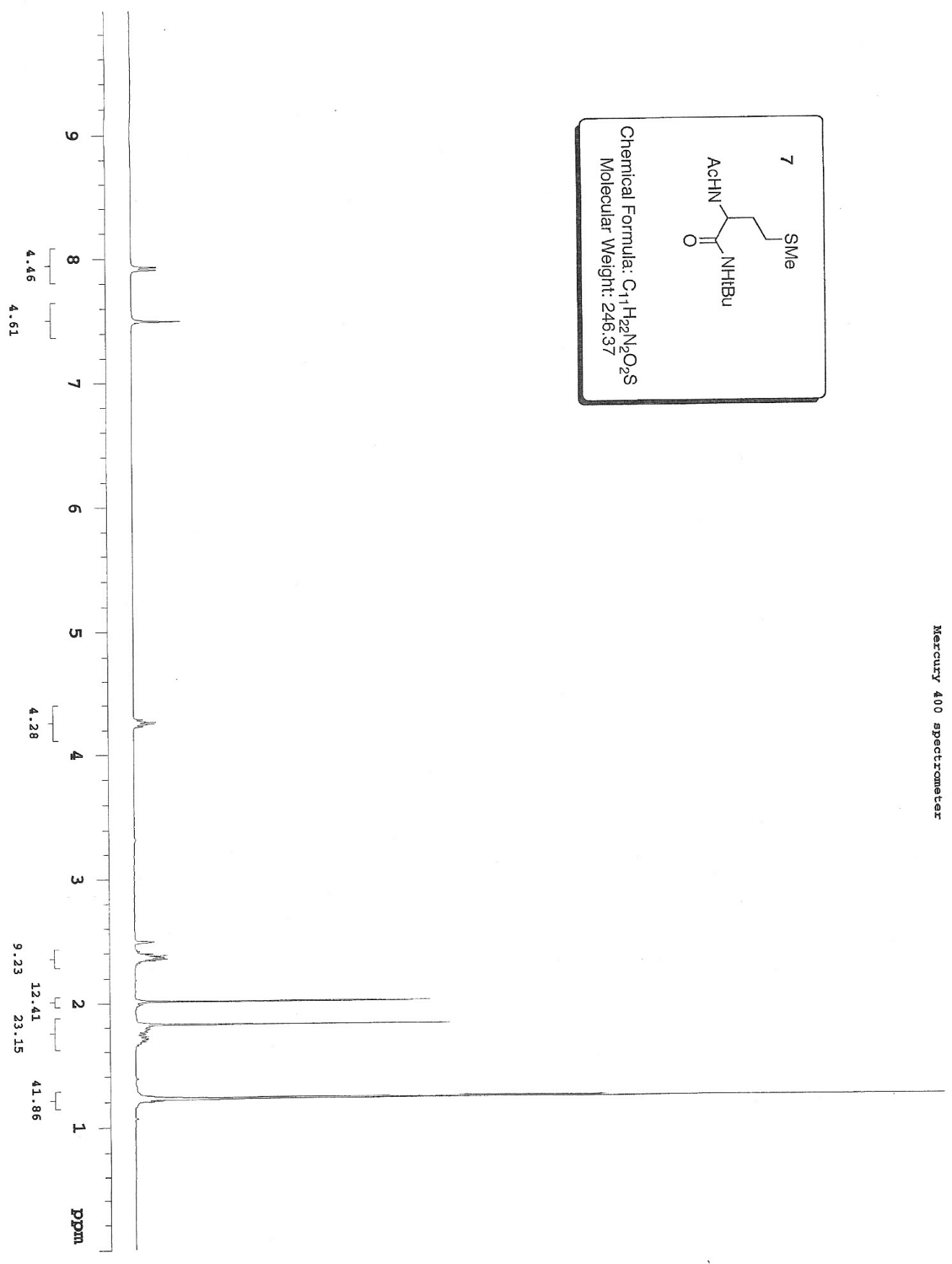



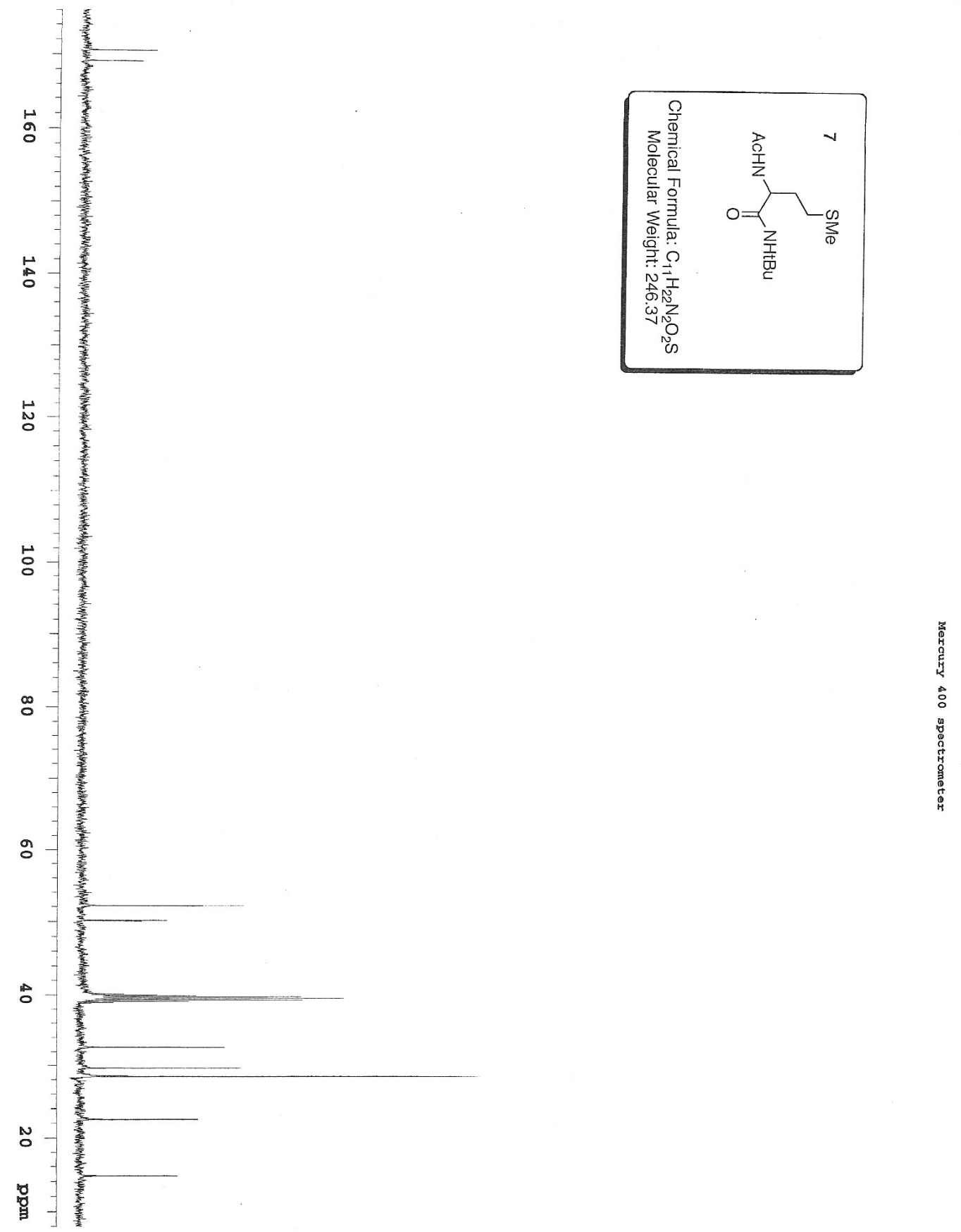
Supporting Information Ekkati, Kodanko*

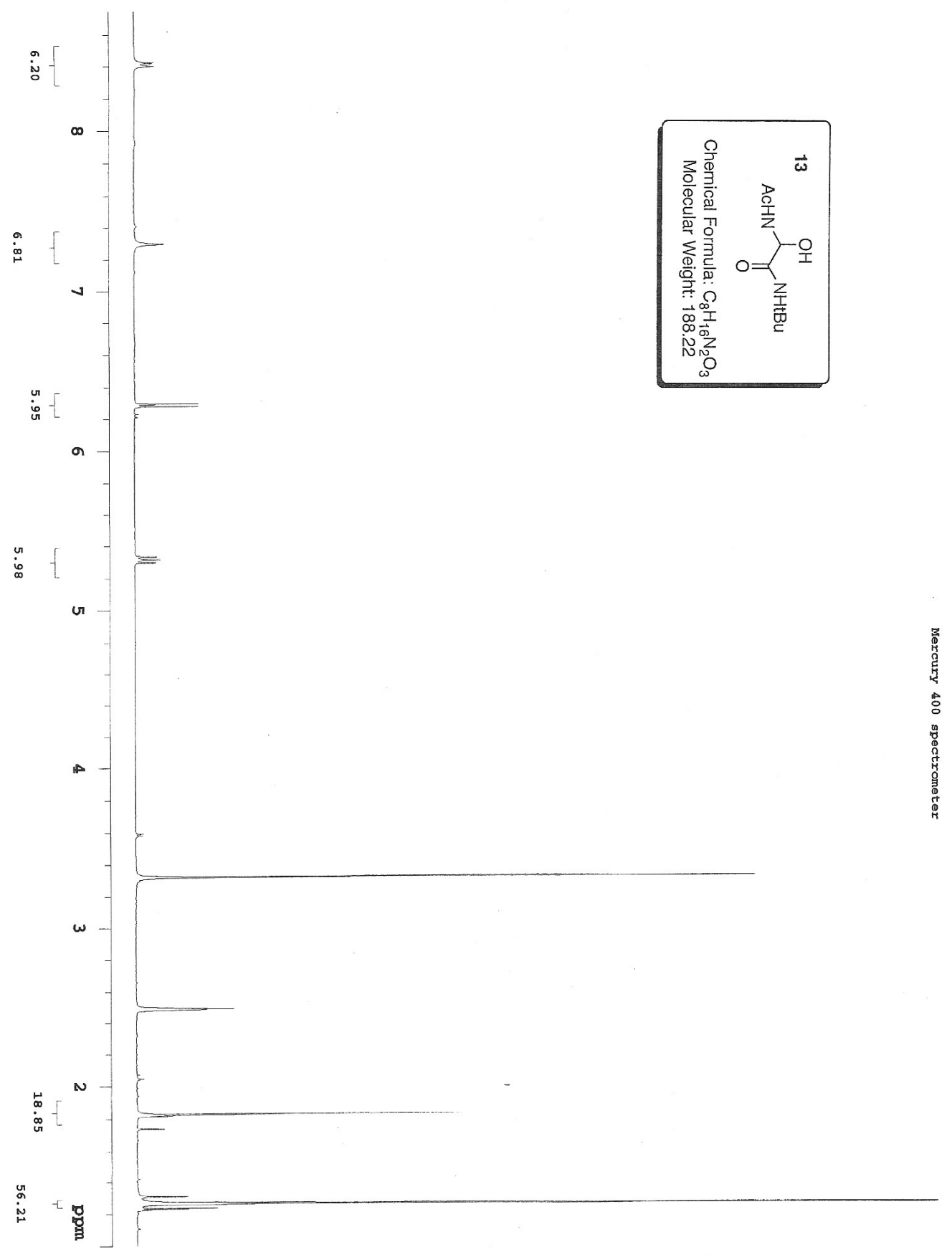




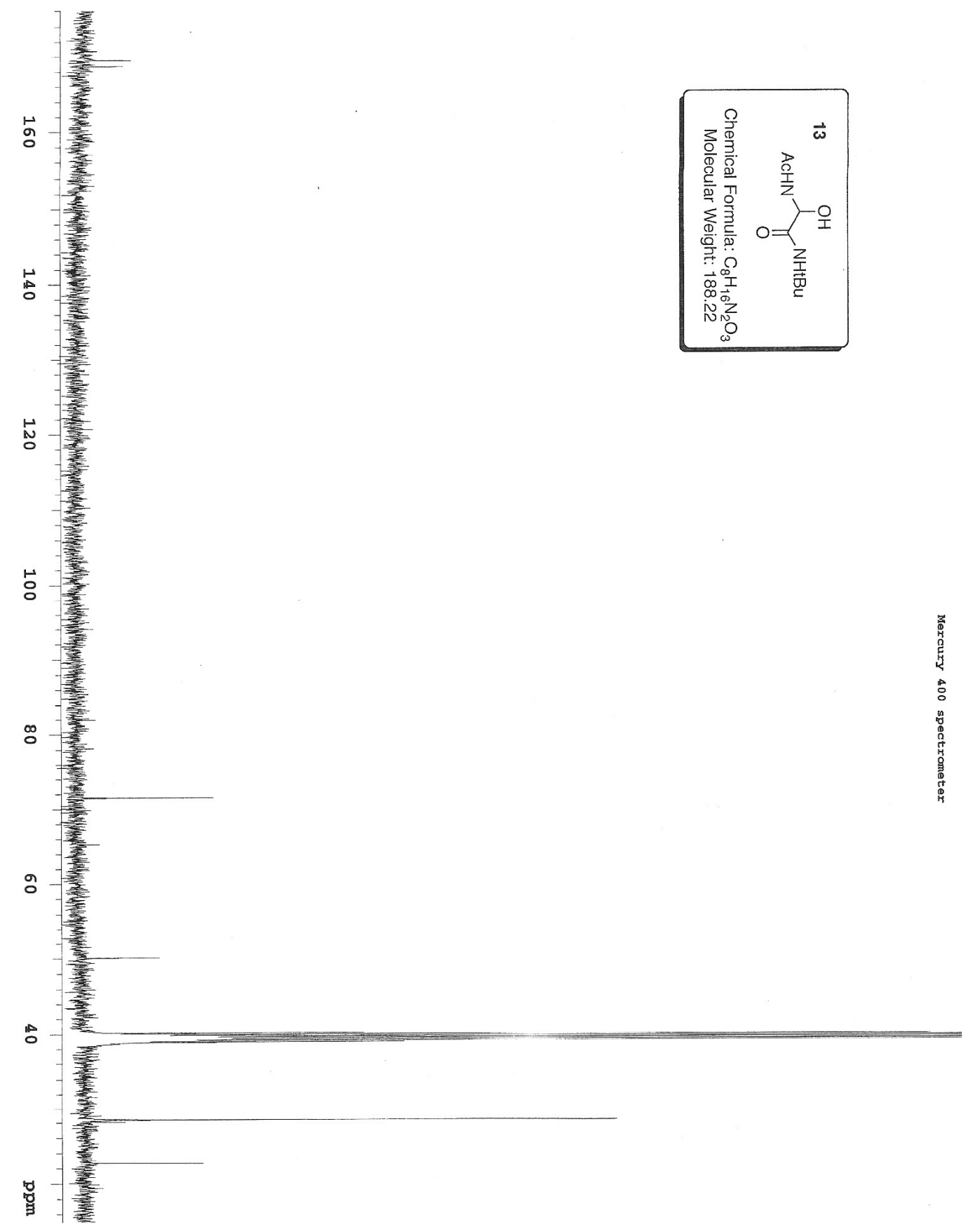


Supporting Information Ekkati, Kodanko*

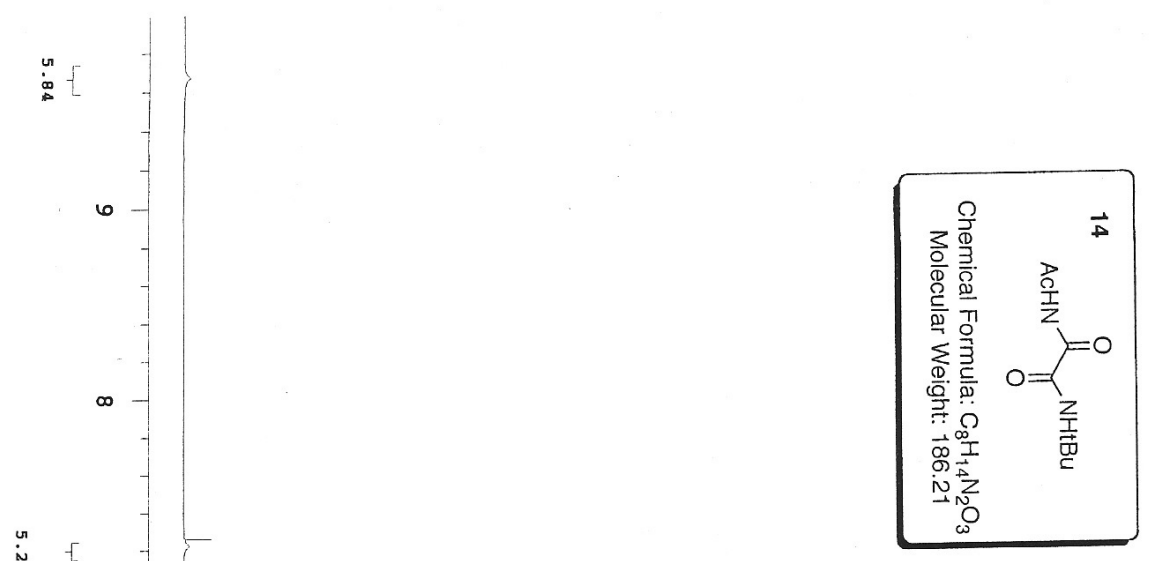


Supporting Information Ekkati, Kodanko*

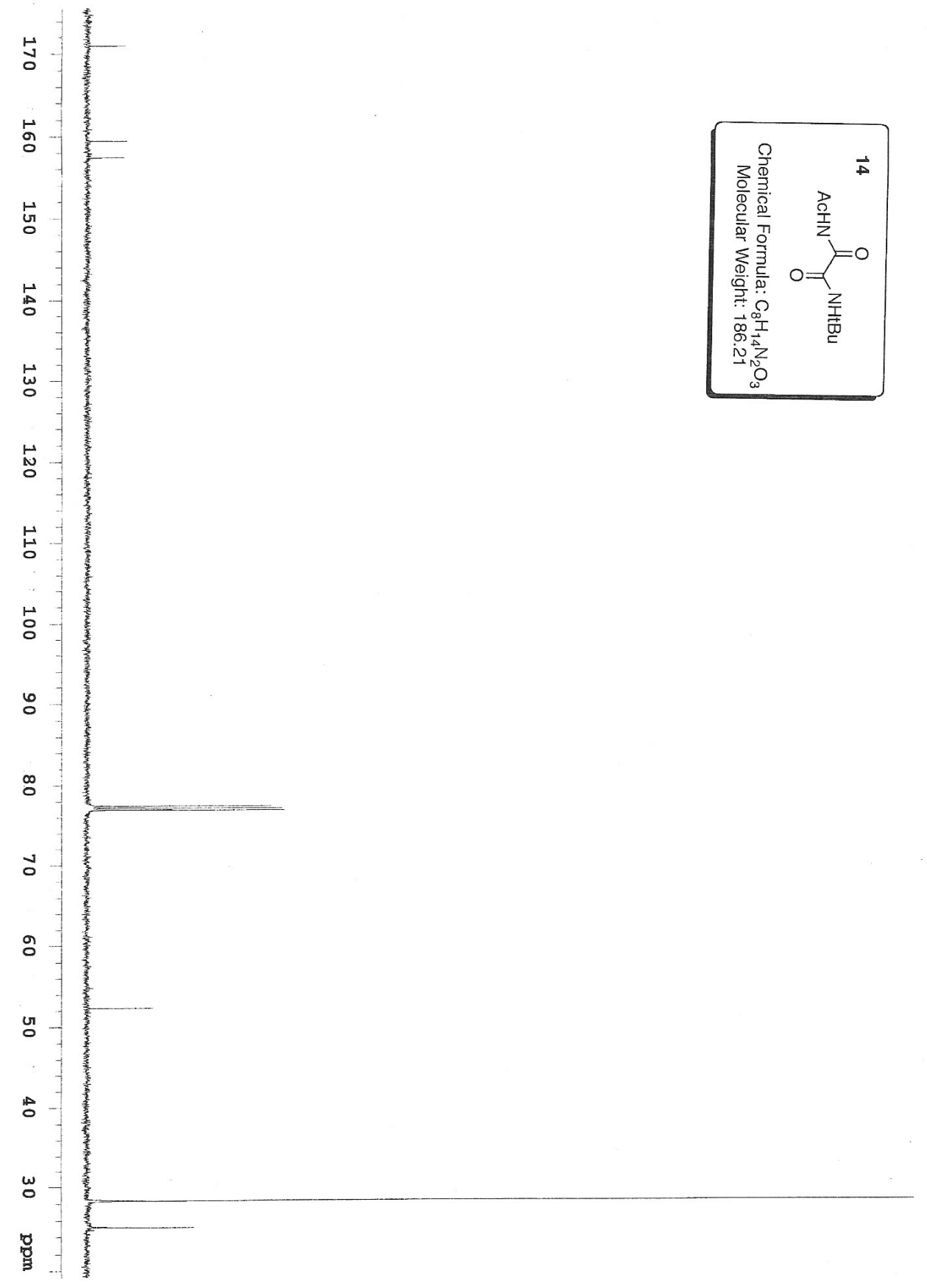




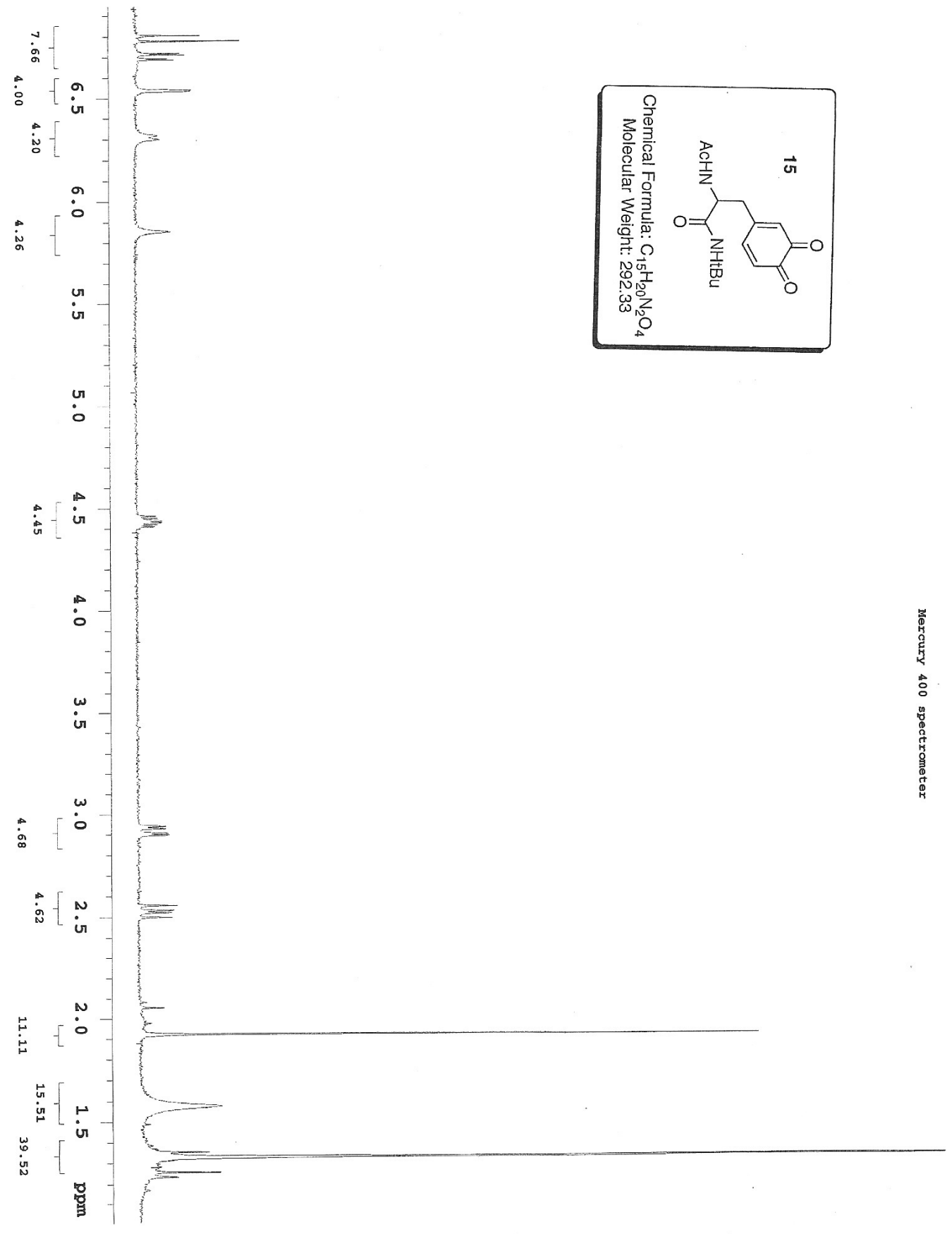




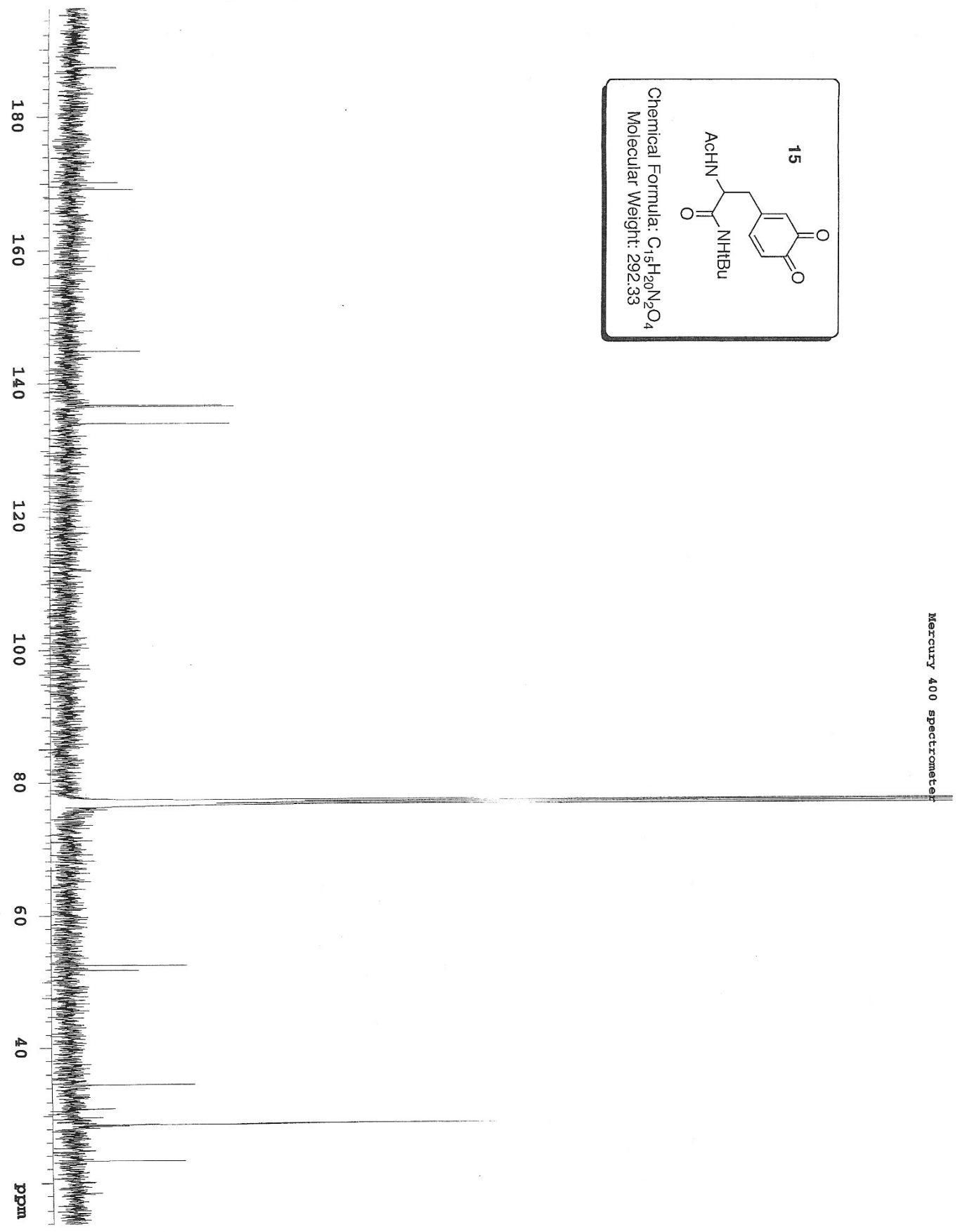




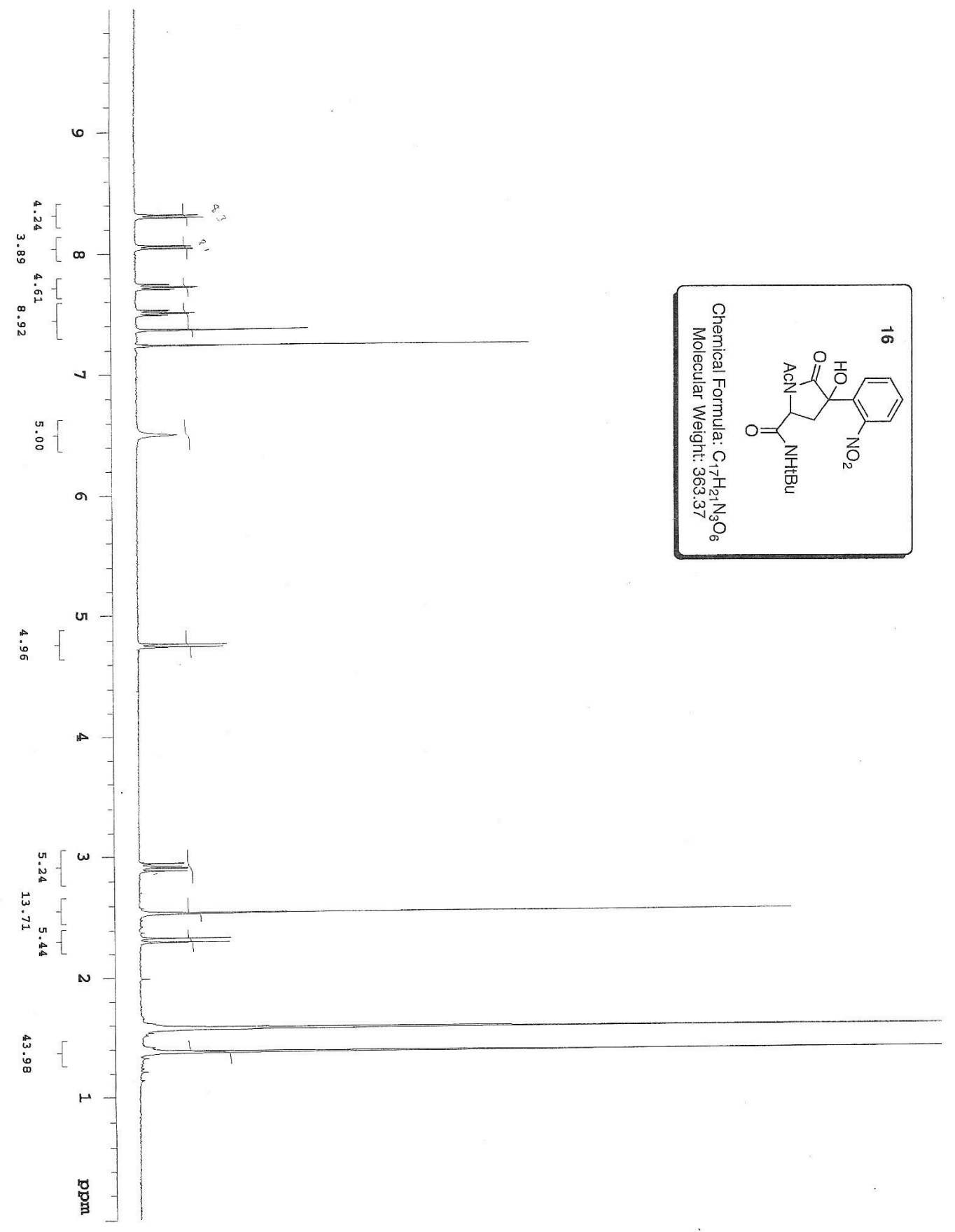




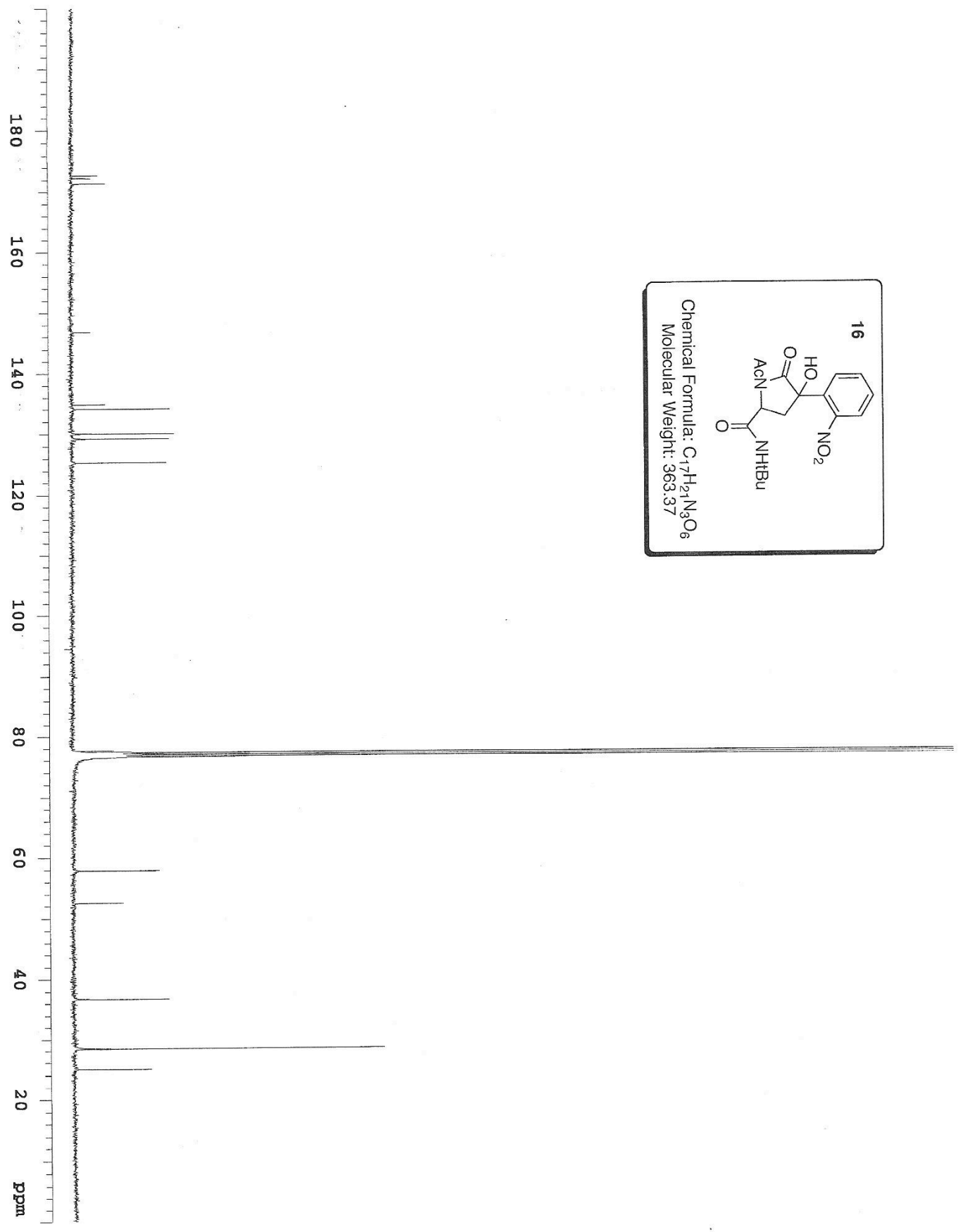


Supporting Information Ekkati, Kodanko*

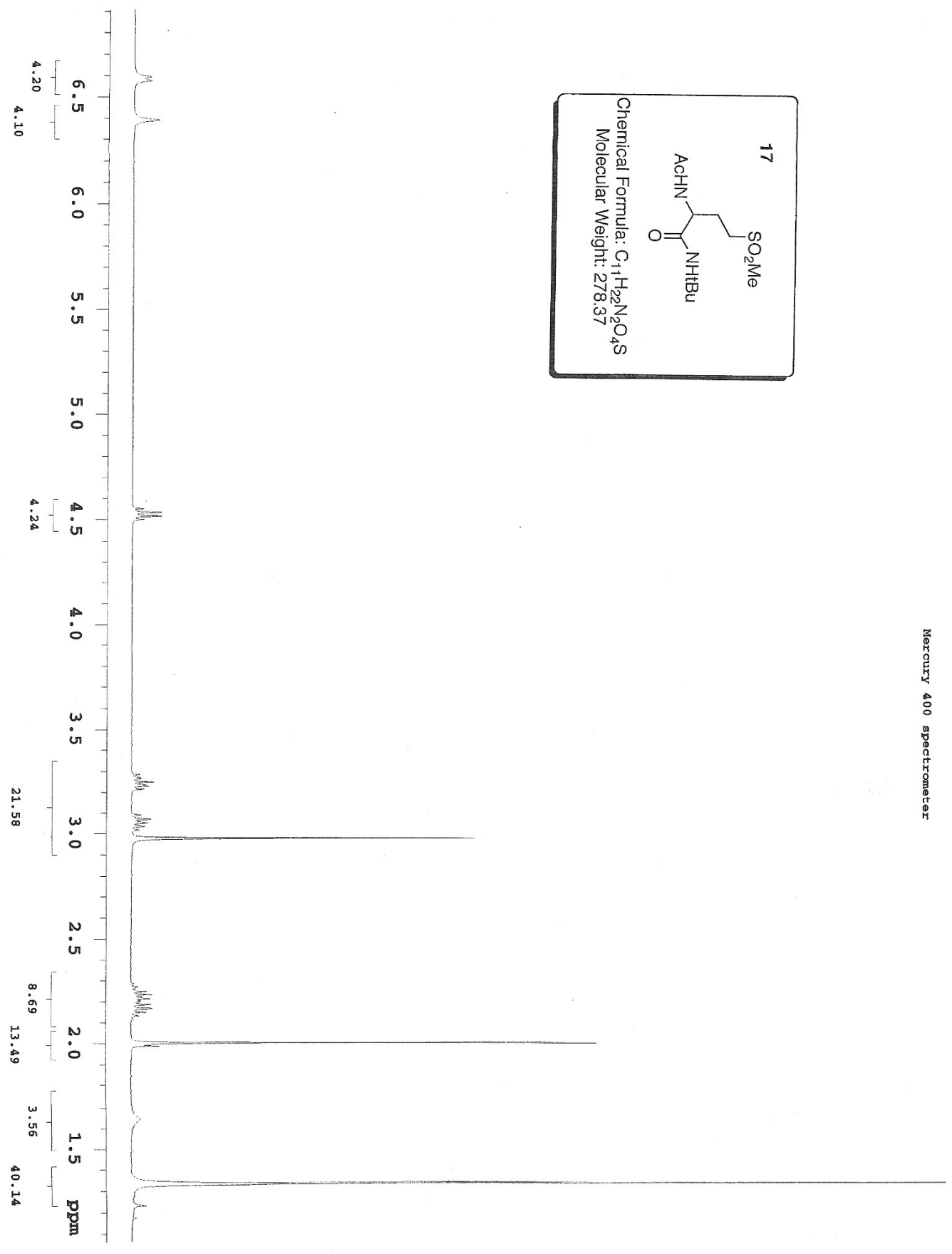




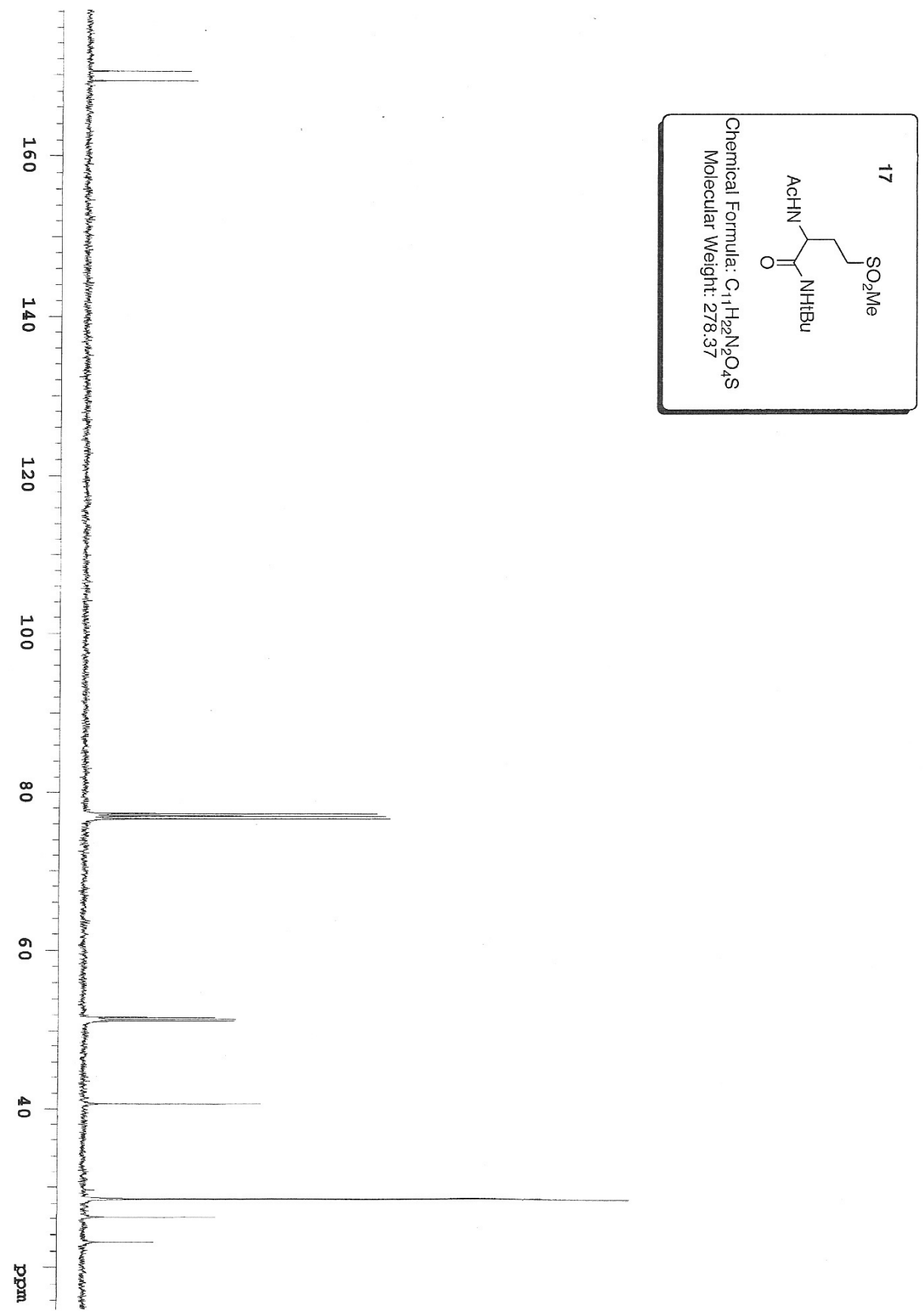

